Revista Brasileira de Cartografia

ISSN 1808-0936 | https://doi.org/10.14393/revbrascartogr

Sociedade Brasileira de Cartografia, Geodésia, Fotogrametria e Sensoriamento Remoto

\title{
Patch Test: Uma revisão teórica e prática
}

\section{Patch Test: A theorical and practical review}

\author{
Italo Oliveira Ferreira ${ }^{1}$, Laura Coelho de Andrade ${ }^{2}$, Felipe Catão Mesquita Santos ${ }^{3}$ e Larissa Messias de Souza ${ }^{4}$ \\ 1 Universidade Federal de Viçosa, Departamento de Engenharia Civil, Viçosa, Brasil. italo.ferreira@ufv.br. \\ ORCID: https://orcid.org/0000-0002-4243-8225 \\ 2 Universidade Federal de Viçosa, Departamento de Engenharia Civil, Viçosa, Brasil. laura.andrade@ufv.br. \\ ORCID: https://orcid.org/0000-0003-3693-2208 \\ 3 Universidade Federal de Viçosa, Departamento de Engenharia Civil, Viçosa, Brasil. felipe.mesquita@ufv.br. \\ ORCID: https://orcid.org/0000-0002-9376-766X \\ 4 Universidade Federal de Viçosa, Departamento de Engenharia Civil, Viçosa, Brasil. larissa.messias@ufv.br. \\ ORCID: https://orcid.org/0000-0002-7767-1131
}

Resumo: O surgimento de sistemas multifeixe aliado ao rápido desenvolvimento tecnologia dos diversos sensores e componentes auxiliares, conduziram a levantamentos mais robustos e precisos. Contudo, a incorreta instalação, alinhamento ou sincronização da instrumentação batimétrica pode depreciar demasiadamente os dados batimétricos. Para sistemas multifeixe, um procedimento de calibração muito empregado consiste no patch test. Esse procedimento determina ângulos residuais relativos entre os sensores de medição angular e o transdutor, com o intuito de corrigir possíveis desvios provenientes do controle dimensional da embarcação. Apesar de bastante difundido e largamente empregado, divergências teóricas e práticas ainda são observadas. Diante disso, o objetivo deste estudo consiste em apresentar uma revisão teórica e prática da metodologia do patch test, avaliando divergências no produto final da calibração, à medida que se altera a sequência e forma do processamento. Para isso, foram coletados dados hidrográficos em dois locais distintos e o processo de calibração foi realizado por meio de duas abordagens (analítica e gráfica), variando a sequência de processamento. Na primeira abordagem, os offsets residuais foram determinados com recurso a equações matemáticas, avaliando a correspondência entre os perfis batimétricos resultantes. A segunda abordagem consistiu numa avaliação qualitativa e gráfica, usualmente empregada pelos softwares hidrográficos.

Palavras-chave: Patch test. Calibração. Batimetria. Multifeixe.

Abstract: The appearance of multibeam systems combined with the rapid development of the technology of the various sensors and auxiliary components had led to more robust and accurate surveys. However, the incorrect installation, alignment or synchronization of the bathymetric instrumentation can depreciate the bathymetric data overly. For multibeam systems, a widely used calibration procedure consists of the patch test. This procedure appoint relative residual angles between the angular measurement sensors and the transducer, in order to correct possible deviations from the vessel's dimensional control. Despite being quite widespread and widely used, theoretical and practical divergences are still observed. Therefore, the objetive of this study is to present a theoretical and practical review of the patch test methodology, assessing divergences in the final calibration product, as the processing sequence and form changes. For this, hydrographic data were collected in two different locations and the calibration process was carried out using two approaches, varying the processing sequence. In the first approach, residual offsets were determined using mathematical equations, evaluating the correspondence between bathymetric surfaces. The second approach consisted of a qualitative and graphical assessment, usually employed by hydrographic software.

Keywords: Patch test. Calibration. Bathymetry. Multibeam. 


\section{INTRODUÇÃO}

O desenvolvimento tecnológico dos ecobatímetros monofeixe culminaram no surgimento dos sistemas de batimetria multifeixe ${ }^{1}$. Diferentemente dos seus antecessores, os ecobatímetros multifeixe são capazes de executar diversas medições de profundidade com um mesmo pulso acústico, obtendo medições da coluna d'água em uma faixa perpendicular à direção de navegação. Dentre as diversas vantagens desta tecnologia destacam-se o elevado ganho em resolução e acurácia e o grande adensamento de dados (USACE, 2013; MALEIKA, 2015, FERREIRA et al., 2019b). Dentre as desvantagens, destacam-se o custo relativamente alto, tanto dos hardwares quanto dos softwares, e a maior complexidade técnica na instalação e manuseio do sistema. Mesmo assim, um número crescente de serviços hidrográficos adotou a tecnologia multifeixe como a metodologia principal para coleta de dados batimétricos visando a produção e atualização da cartografia náutica (IHO, 2008; INSTITUTO HIDROGRÁFICO, 2009; LINZ, 2010; NOAA, 2011; USACE, 2013; DHN, 2017).

Um sistema multifeixe é composto por diversos sensores e componentes, tais como, ecobatímetro multifeixe, receptores GNSS (Global Navigation Satellite System) e os sensores de medição angular que fornecem a atitude e a direção da plataforma de sondagem, isto é, sensores de movimento (IMU - Inertial Measurement Unit; MRU - Motion Reference Unit, etc.) e girobússolas (sensores de proa), respectivamente. Para que as informações obtidas por estes diversos sensores possam ser sincronizadas, faz-se necessário o conhecimento da posição tridimensional de cada sensor em relação ao sistema de coordenadas da embarcação (referencial da embarcação) ou, pelo menos, a posição relativa entre os sensores. Segundo Clarke (2003), esta é uma fase crítica no processo de integração de um sistema de sondagem multifeixe. Incertezas envolvidas neste procedimento conduzirão a incertezas horizontais e verticais na medição da profundidade reduzida, afetando a qualidade dos dados batimétricos.

A principal metodologia utilizada atualmente para materialização do sistema de referência da embarcação, com consequente obtenção dos afastamentos característicos dos sensores em relação ao ponto de referência (offsets lineares) e dos desalinhamentos angulares (offsets angulares) dos diversos sensores, consiste basicamente em posicionar a embarcação de sondagem em doca-seca ou em berços e efetuar medições topográficas a partir de pontos coordenados em terra (CLARKE, 2003; PEIRIÇO et al., 2005; SOUZA; KRUEGER, 2009; NARDEZ et al., 2016; CLARKE, 2014; DHN, 2017).

Tais medições topográficas são conduzidas visando obter resultados com alto nível de precisão, mesmo assim, não raro, ainda existirão resíduos após a instalação, especialmente, angulares. Deste modo, a realização de uma calibração em campo objetivando obter e corrigir estes resíduos se faz necessário. O procedimento comumente aceito e empregado é o patch test, etapa muito importante e necessária para a aquisição de dados multifeixe mais confiáveis e acurados. A partir deste procedimento, é possível identificar e quantificar os seguintes parâmetros residuais: roll offset, pitch offset e heading offset, além da possível latência (delay time) entre o sistema de posicionamento e o ecobatímetro, o que poderá causar erros de posicionamento da profundidade coletada (GODIN, 1998; MANN, 1998; GUERIOT et al., 2000; IHO, 2005, FERREIRA et al., 2016).

Segundo Godin (1998), o patch test é um procedimento de calibração que envolve a coleta de dados batimétricos seguindo as linhas planejadas em relevos submersos com formatos específicos e posterior processamento, com o objetivo de identificar resíduos existentes e corrigir o alinhamento dos sensores do sistema multifeixe, mais especificamente, o alinhamento relativo entre a cabeça do sonar (transdutor) e os sensores de medição angular (atitude e direção). Deve-se destacar que, como supracitado, o procedimento em questão determina os ângulos residuais relativos entre o transdutor e o sensor de movimentos e/ou sensor de proa, não fornecendo quaisquer medidas em relação aos sistemas de coordenadas (absoluto) da plataforma de sondagem.

A obtenção dos resíduos nos offsets angulares por meio do patch test segue um ordenamento lógico durante o processamento, isto é, após a coleta dos dados, alguns parâmetros são obtidos primeiramente. Tal ordenamento, não necessário durante a coleta de dados, pode depender, na maioria das vezes, do software

\footnotetext{
${ }^{1}$ Neste artigo, o termo multifeixe é usado em referência aos ecobatímetros multifeixe que empregam a técnica de formação de feixes nas estimativas de profundidade.
} 
hidrográfico empregado. Os softwares Hypack (HYPACK, 2020) e Caris Hips and Sips (TELEDYNE CARIS, 2020), por exemplo, sugerem iniciar o processamento com o teste de latência, quando necessário, seguidos do pitch, roll e heading. Já o software PDS 2000 (TELEDYNE, 2018) sugere a sequência latência, roll, pitch e heading.

Apesar de amplamente utilizado, observa-se em literaturas especializadas divergências sobre a realização do patch test, especialmente no que concerne sequência de calibração adotada. Godin (1998), Mann (1998) e IHO (2005) utilizam a seguinte ordenação: latência, pitch, heading e roll. Já Gueriot et al. (2000) e Lekkerkerk et al. (2006) recomendam: latência, roll, pitch, heading. Battista e Stecher (2007) usaram o sequenciamento latência, pitch, roll e heading. Por fim, Eisenberg et al. (2011), utilizam a seguinte sequência: latência, roll, heading e pitch para estimar os resíduos angulares de um sonar interferométrico (Phase Differencing Bathymetric Sidescan Sonar).

Segundo IHO (2005), a latência deve ser o primeiro parâmetro obtido, uma vez que um atraso entre o sistema de posicionamento e o ecobatímetro pode acarretar em incertezas na determinação, por exemplo, do offset em pitch. Há de se evidenciar que nos sistemas integrados, isto é, sistemas multifeixe cujo sensores inerciais e de posicionamento são fisicamente e eletronicamente integrados, na prática não observa-se qualquer latência. Outrem, as pesquisas multifeixe são conduzidas com sincronização de tempo muito precisa, usando a hora do GPS (Global Positioning System) e um sincronizador do tipo PPS BOX (pulso por segundo). Em todos os casos, o teste de latência deve ser realizado com a finalidade de comprovar que a latência é zero ou não significativa. De acordo com Eisenberg et al. (2011), o patch test, da forma em que é apresentado por Godin (1998), pode se mostrar ineficaz na calibração de sistemas multifeixe (interferométricos) devido à algumas características que dificultam o isolamento e a resolução das incertezas.

Diante disso, o objetivo deste trabalho é apresentar uma revisão teórica e prática do patch test e avaliar, por meio de duas abordagens distintas, se a sequência de processamento e obtenção dos offsets residuais, ocasiona divergências significativas no resultado final do processo de calibração. Para tal, foram selecionadas duas áreas distintas, localizadas em São Francisco do Sul - SC e em Santos - SP, onde foram executadas levantamentos hidrográficos com diferentes sistemas multifeixe. Os dados coletados foram, então, processados por meio de um algoritmo iterativo e semiautomático implementado em ambiente $\mathrm{R}$, auxiliado pelo software Hypack, ferramentas de desenho assistido por computador e planilhas de cálculos.

\section{PATCH TEST}

Diversas são as fontes de incerteza que depreciam a qualidade dos dados batimétricos coletados com recurso a sistemas de sondagem multifeixe. Para aquisição de dados confiáveis, deve-se garantir, idealmente, o alinhamento perfeito entre o sistema de coordenadas da embarcação e os sistemas de eixos dos sensores a bordo. A Figura 1 ilustra os eixos do sistema de coordenadas de uma típica plataforma de sondagem multifeixe, bem como a disposição dos equipamentos a bordo e o sistema de eixos de cada sensor.

Figura 1 - Embarcação de sondagem multifeixe com a disposição dos equipamentos a bordo.

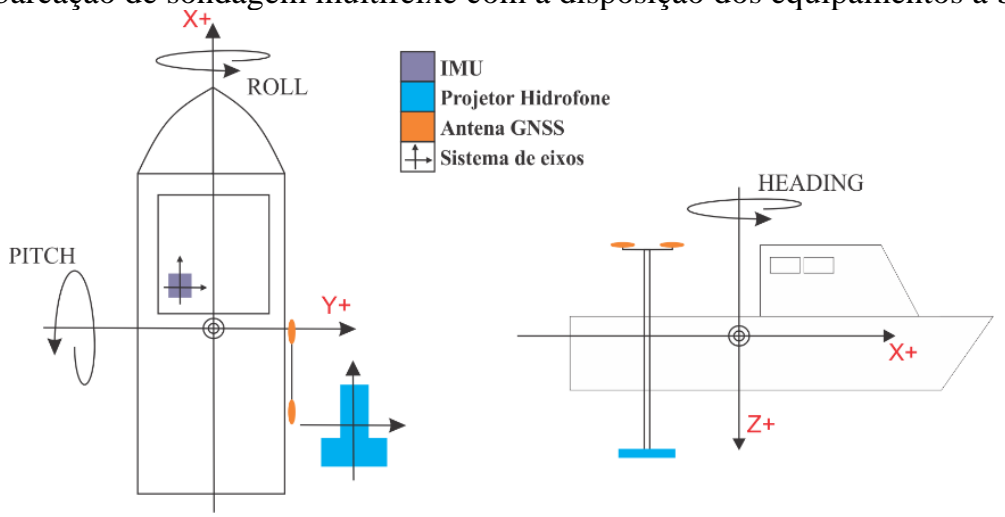

Fonte: Os autores (2021).

Segundo a R2 Sonic (2017), uma incerteza de $1^{\circ}$ em roll, numa distância inclinada de 50 metros, pode causar um erro de até 0,60 metros na medição da profundidade. Ao passo que a mesma incerteza em pitch, irá 
produzir um erro na posição de cerca de 0,40 metros numa profundidade de 25 metros. Portanto, pode-se perceber que incerteza em roll afeta prioritariamente a profundidade enquanto o pitch afeta a posição.

Durante a instalação dos sensores e sistemas, os afastamentos lineares e angulares são determinados com alta precisão, no entanto, em quase todos os casos, ainda existirão resíduos nas observações. Os resíduos angulares existentes entre o transdutor e os sensores atitude e direção são resolvidos por meio do patch test (GODIN ,1998; IHO, 2005). Entende-se por resíduos angulares de montagem, quaisquer desalinhamentos angulares entre o transdutor multifeixe e os sensores de medição angular (IMU, Sensores de proa, etc.).

O patch test consiste num processo de calibração em que são coletados linhas de sondagem em dois diferentes tipos de relevo. Para estimar o resíduo em roll é necessário sondar um fundo plano. Canais dragados e áreas de ancoragem são boas escolhas. Para coleta de dados visando resolver o pitch, heading e a latência (quando necessário), deve-se buscar uma área com relevo submerso variável. Muito embora um talude, de um canal de navegação por exemplo, possa ser útil, recomenda-se sempre dar preferência a feições submersas bem definidas e em áreas com maiores profundidades (a partir de 50 metros), tais como dutos submarinos, afloramentos rochosos e destroços. Taludes ou áreas inclinadas geralmente são encontrados em locais rasos, que não possuem profundidades suficientes para a solução adequada, especialmente do pitch (GUERIOT et al.,2000; EISENBERG et al., 2011).

Geralmente, na prática, os hidrógrafos coletam apenas dados suficientes para obter os offsets angulares residuais e a latência. Entretanto, deve-se destacar que quanto mais dados forem coletados, mais testes podem ser executados e, por conseguinte, uma maior confiabilidade será alcançada (WHEATON,1998). A grande maioria dos sistemas multifeixe comercializados atualmente incorporam a sincronização da hora do GPS e, assim, não espera-se latência no posicionamento. Entretanto, é sempre recomendável executar o teste de latência visando comprovar que, para todos os efeitos práticos, a latência é nula.

Basicamente, existem duas formas distintas de efetuar o processamento do patch test. A primeira consiste numa abordagem interativa, em que o hidrógrafo efetua medidas dos deslocamentos entre os perfis analisados e estima os offsets residuais por meio de equações matemáticas (aqui chamado de método analítico). Esse processo foi muito usado no passado (GODIN, 1998). A segunda é uma abordagem automática e é mais comum entre os softwares hidrográficos atuais. No geral, aplica-se um determinado offset nos perfis e estimase o RMS (Root Mean Square) por meio da comparação entre as profundidades dos perfis. Faz-se isso para vários valores de offsets, gerando-se um gráfico. O offset correspondente ao menor valor de RMS é geralmente o adotado (aqui chamado de método gráfico). Embora, estes sejam os métodos comumente empregados, algoritmos nem tão recentes são capazes de determinar os valores residuais automaticamente por meio de técnicas de correspondência entre as superfícies (surface match) (QPS, 2014; HYPACK, 2020; TELEDYNE CARIS, 2020). Nas próximas seções será discutido em detalhes o aqui denominado método analítico. O método gráfico, por sua vez, é demasiado simples e, assim, optou-se por elucidá-lo nas seções 3 e 4 .

Para validar o patch test, recomenda-se, após o processamento e inserção apropriada dos valores de offsets angulares residuais e a latência (se aplicável), buscar um objeto submerso, idealmente de fácil identificação, e sondá-lo de todos os lados. Se a representação do objeto, com todas as linhas levantadas, for idêntica, significa que o patch test foi executado e processado adequadamente. Muito embora estes procedimentos sejam negligenciados na prática.

\subsection{Latência residual}

A determinação da latência é realizada, prioritariamente, a partir da sondagem de uma linha sobre um fundo submerso plano, contendo uma feição ou estrutura bem definida, como por exemplo, afloramentos rochosos, cascos soçobrados, dutos, dentre outros. Na inobservância destes requisitos, pode-se sondar linhas perpendiculares à taludes inclinados entre $10^{\circ}$ a $20^{\circ}$ com comprimento de pelo menos 200 metros, para a definição de uma amostra satisfatória (GODIN, 1998; HYPACK, 2020).

A partir da mesma linha planejada, com a embarcação na mesma direção, dois conjuntos de dados são coletados com duas velocidades diferentes (a sondagem da linha deve ser realizada duas vezes). A linha é sondada na velocidade padrão de pesquisa, o que irá assegurar uma boa navegabilidade da embarcação e, em seguida, novamente na mesma direção, mas a uma velocidade que deve ser metade da velocidade padrão de 
levantamento. Se a embarcação não puder percorrer a linha com a metade da velocidade padrão, deve-se sondar a linha com uma velocidade mínima e novamente com a máxima velocidade possível, porém isso poderá influenciar os resultados, devido aos movimentos de squat ou settlement (R2 Sonic, 2017). A latência ( $\delta$ t) entre o sistema de posicionamento e o ecobatímetro é evidenciada a partir de uma diferença entre os perfis levantados (Figura 2) e pode ser estimada por meio da Equação 1 (GODIN, 1998; GUERIOT et al., 2000; IHO, 2005; LEKKERKERK et al., 2006):

$$
\delta t=\frac{\delta x}{v_{1}-v_{2}}
$$

Em que $\delta x$ é o deslocamento horizontal (no sentido da navegação) entre os perfis levantados e $v_{1}, v_{2}$ são as velocidades de navegação, sendo $v_{1}$ a maior velocidade. O parâmetro $\delta x$ é definido por meio da média aritmética de deslocamentos medidos sobre os perfis das linhas sondadas. Este processo é iterativo e é realizado até que se alcance uma diferença mínima entre os perfis de levantamento, sendo esta, permitida por uma tolerância pré-definida.

Figura 2 - Esquema de sondagem e solução do teste de latência.
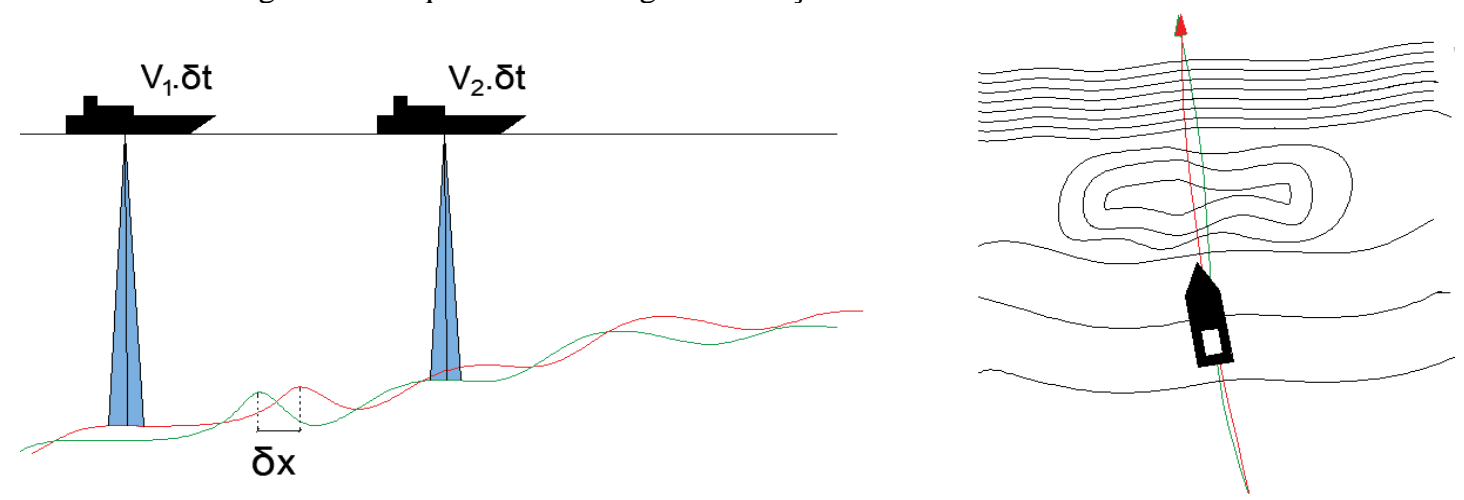

Fonte: Os autores (2021).

Como discutido, nos dias de hoje os sistemas de sondagem multifeixe comercializados incorporam a sincronização da hora do GPS e, assim, não espera-se latência na posição do GPS. No entanto, a maioria dos algoritmos de patch test não produzirão latência zero, mas o valor derivado é geralmente tão pequeno que se constitui em um zero prático.

\subsection{Offset residual em pitch}

O offset residual em pitch é determinado seguindo a mesma metodologia e área submersa discutida no teste da latência, contudo, empregam-se duas linhas com sentidos de navegação opostos e mesmas velocidades. É importante que a cabeça do sonar passe exatamente sobre a parte submersa inclinada durante as duas execuções (R2 Sonic, 2019).

A principal característica do offset em pitch é que o deslocamento horizontal gerado na direção da navegação é proporcional à profundidade sendo maior em áreas mais profundas, daí a importância de se executar este teste em áreas com grandes profundidades. Via de regra, águas rasas não fornecerão bons resultados (GODIN, 1998; GUERIOT et al., 2000; IHO, 2005; LEKKERKERK et al., 2006) (Figura 3).

O offset residual em pitch $\left(\delta \theta_{P}\right)$ pode ser obtido pela Equação 2 (GODIN, 1998; IHO, 2005):

$$
\delta \theta_{P}=\left(\frac{\frac{\Delta x}{2}}{z}\right)
$$

Sendo $\Delta x$ o deslocamento horizontal (no sentido da navegação) entre os perfis das linhas próximo ao nadir e z é a profundidade à nadir. Para a obtenção de $\Delta x$, realiza-se algumas medições dos deslocamentos sobre os perfis das linhas e calcula-se a média. Este processo deve ser iterativo até que se tenha uma pequena 
diferença entre os perfis, menor que uma tolerância pré-definida.

Figura 3 - Esquema de sondagem e solução do teste de pitch.
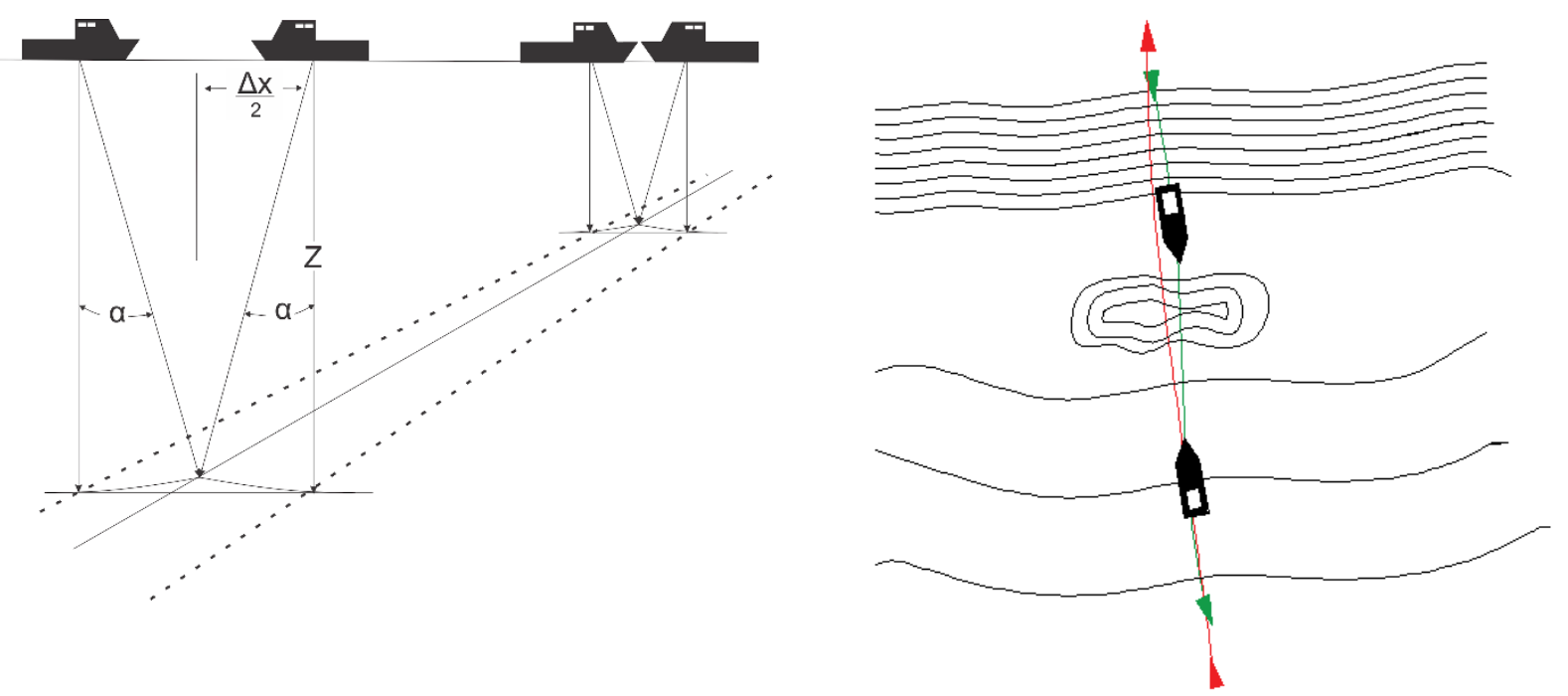

Fonte: Adaptada de Godin (1998).

\subsection{Offset residual em heading}

Para a determinação do offset residual em heading, também conhecido como yaw ou proa, o levantamento é feito a partir de duas linhas adjacentes em um fundo com inclinação ou sobre uma feição bem definida num fundo plano, mesmos locais escolhidos para os testes anteriores. Os objetos a serem sondados necessitam ter um tamanho suficiente para garantir uma boa amostra e formato sem faces com quinas ou pontas. Ademais, deve-se assegurar que a velocidade de sondagem forneça uma sobreposição de no mínimo $15 \%$ entre as linhas adjacentes. Havendo algum resíduo em heading, os objetos levantados estarão em posições diferentes nos dois conjuntos de dados, isto é, qualquer desalinhamento horizontal entre a cabeça do sonar e os sensores de proa causarão incertezas posicionais, assim como offsets residuais em pitch e latência.

Por outro lado, caso seja adotado uma área inclinada, haverá um deslocamento entre os perfis obtidos. O erro causado por resíduos em heading nos pulsos sonoros nadirais é negligenciável, mas aumenta para os feixes externos (GODIN, 1998; GUERIOT et al., 2000; IHO, 2005; LEKKERKERK et al., 2006) (Figura 4).

O offset residual em heading $(\delta \alpha)$ pode ser obtido pela Equação 3 (IHO, 2005):

$$
\delta \alpha=\tan ^{-1}\left(\frac{\Delta x}{\Delta L}\right)
$$

Em $\Delta x$ é o deslocamento horizontal da feição levantada a partir das linhas adjacentes e $\Delta L$ é a distância entre as mesmas. Para a obtenção de $\Delta x$, realiza-se algumas medições dos deslocamentos sobre os perfis da feição levantada e calcula-se a média aritmética. Este processo deve ser iterativo até que se tenha uma pequena diferença entre os perfis, menor que uma tolerância pré-definida. 
Figura 4- Esquema de sondagem e solução do teste de heading.
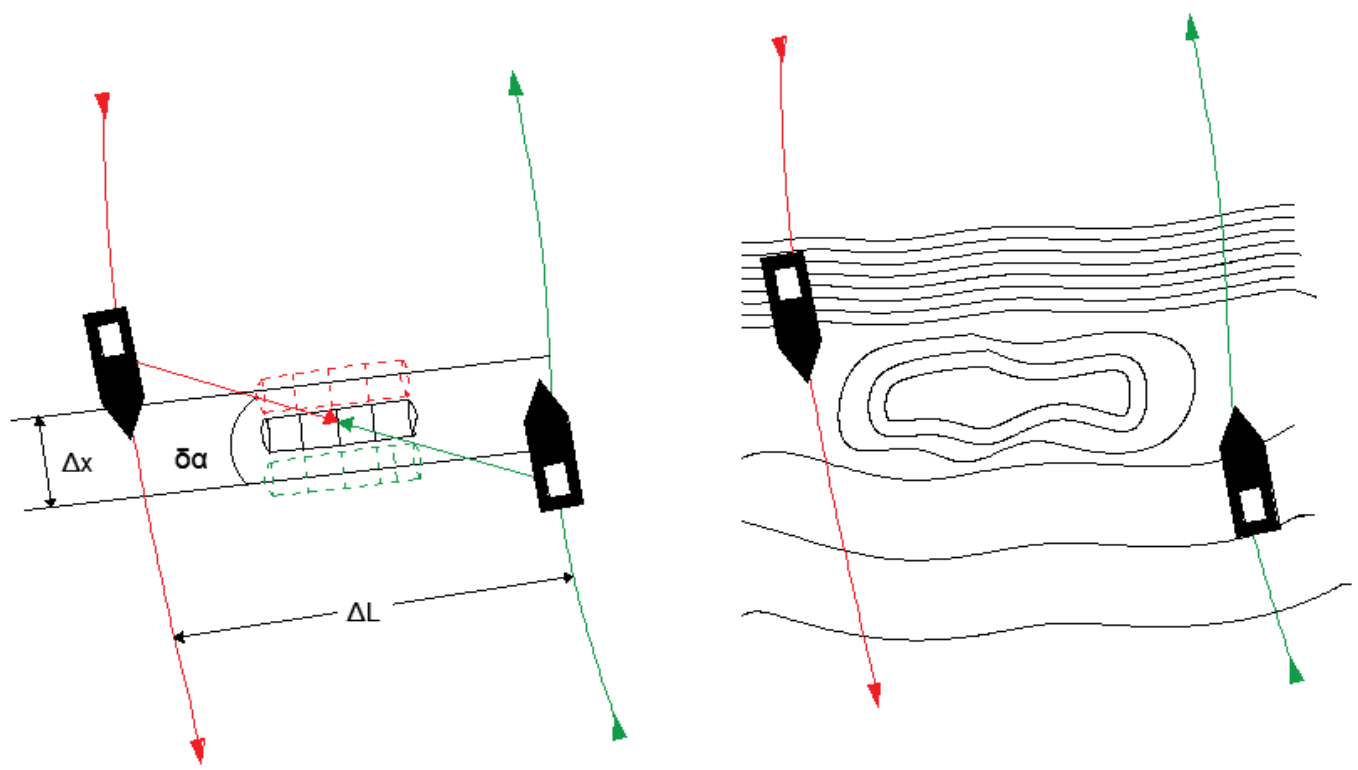

Fonte: Adaptada de IHO (2005).

Cabe ressaltar que a experiência tem mostrado que a solução do heading geralmente é, dos quatro testes que compreendem o patch test, o mais difícil de executar, tanto na prática quanto computacionalmente.

\subsection{Offset residual em Roll}

A metodologia para a determinação do offset residual em roll é similar à adotada para o cálculo do offset residual em pitch. Isto é, empregam-se duas linhas com sentidos de navegação opostos e mesmas velocidades. Todavia, neste caso, o fundo submerso escolhido para execução do teste deve ser plano ou suavemente ondulado. O roll é talvez o parâmetro mais crítico na rotina do patch test, um erro no roll resultará em um erro nas profundidades sondadas. Entretanto, o cálculo para determinar este desalinhamento é, geralmente, o mais fácil e mais consistente. Sugere-se que este teste seja executado em águas mais profundas, para que o deslocamento causado torne-se mais perceptível. Ao visualizar os perfis levantados, observa-se a formação de um "X" entre as linhas levantadas (GODIN, 1998; MANN, 1998; GUERIOT et al., 2000; IHO, 2005; LEKKERKERK et al., 2006b) (Figura 5).

O offset residual em roll $\left(\delta \theta_{R}\right)$ pode ser obtido pela Equação 4 (IHO, 2005):

$$
\delta \theta_{R}=\tan ^{-1}\left(\frac{\frac{\Delta z}{\Delta y}}{2}\right)
$$

Sendo $\Delta z$ o deslocamento vertical entre os pulsos mais externos do feixe de varredura das linhas recíprocas e $\Delta y$ é o deslocamento em y entre o nadir e o pulso mais externo do feixe de varredura. O $\Delta y$ e $\Delta z$ são obtidos a partir de medições dos deslocamentos horizontais sobre os perfis das linhas recíprocas, ao final, calcula-se a média. Este processo deve ser iterativo até que se tenha uma pequena diferença entre os perfis, menor que uma tolerância pré-definida. 
Figura 5 - Esquema de sondagem e solução do teste de roll.
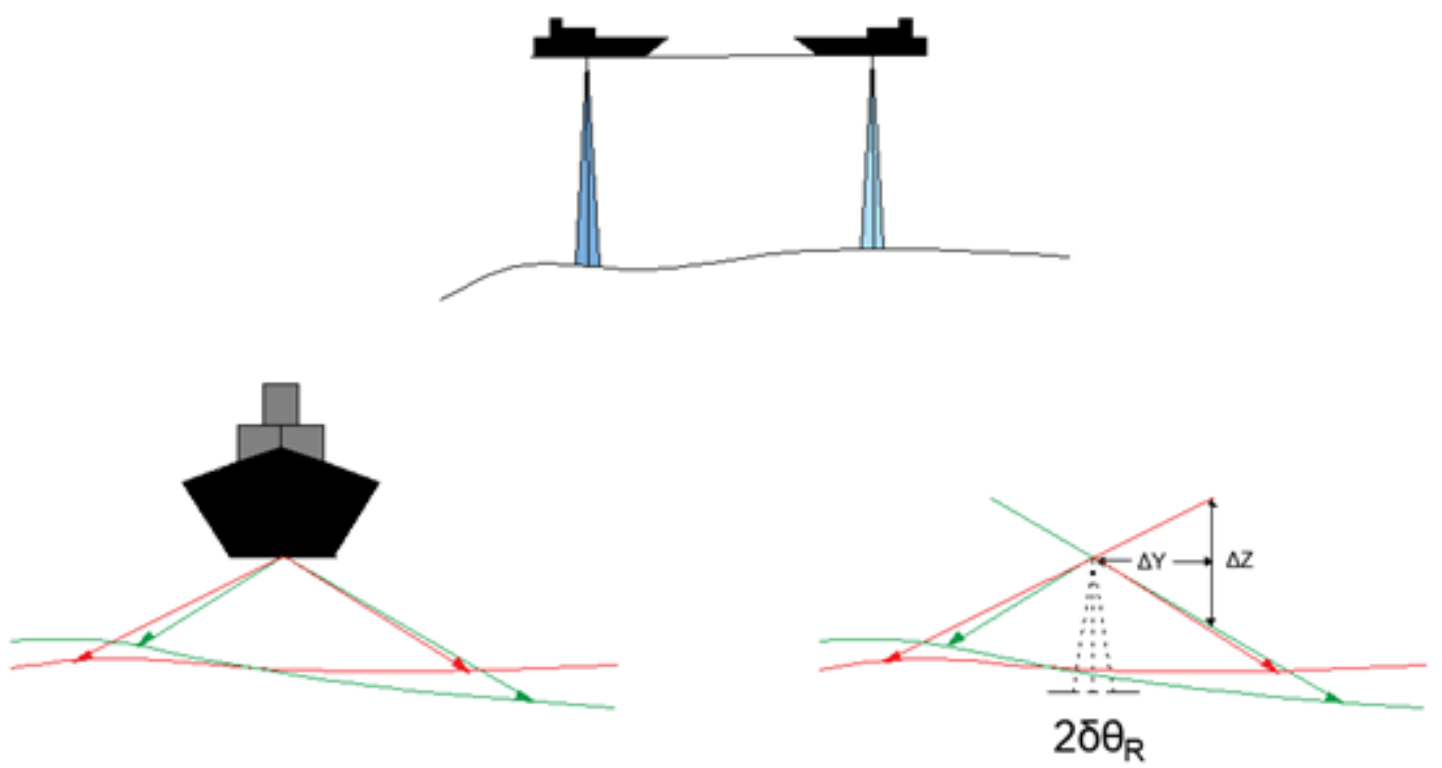

Fonte: Adaptada de Godin (1998).

\section{EXPERIMENTO}

A realização desta pesquisa seguiu as etapas descritas no fluxograma abaixo (Figura 6).

Figura 6 - Fluxograma da metodologia.

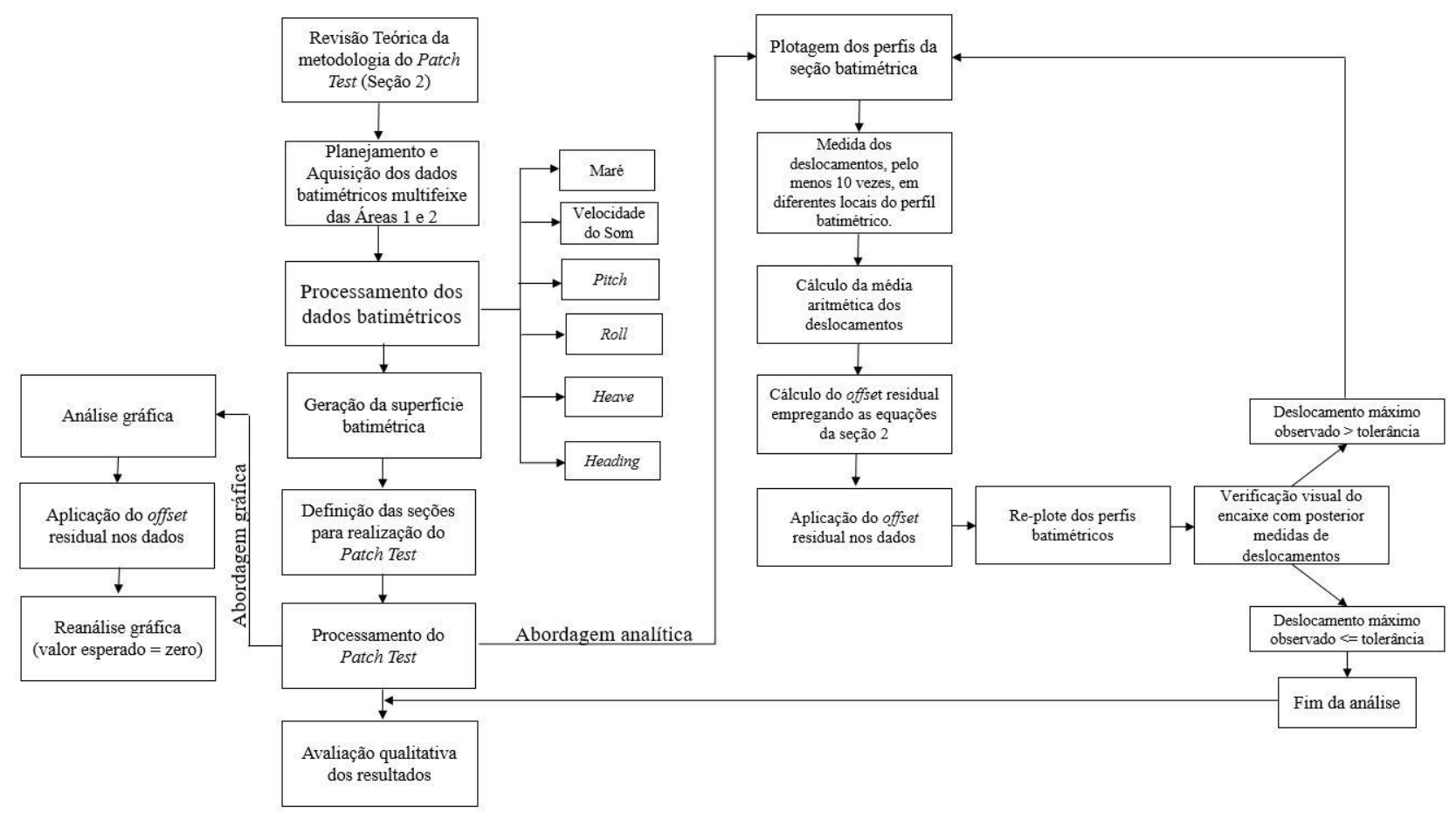

Fonte: Os autores (2021).

Conforme abordado no item 2, o procedimento de execução do patch test pode ser amplamente encontrado em diversas literaturas, tais como Godin (1998); Mann (1998); Gueriot et al.(2000); IHO (2005); Lekkerkerk et al. (2006); Eisenberg et al. (2011) e Hypack (2020). Apesar das inúmeras divergências encontradas, a decisão sobre a escolha dos relevos mais adequados para execução do teste de calibração é unânime entre todos os autores.

Para que os objetivos do trabalho fossem alcançados foram obtidos dados de duas áreas de estudo onde foram realizados levantamentos batimétricos com a tecnologia multifeixe (formadores de feixe). Estas áreas foram selecionadas com objetivo de garantir que os relevos submersos apresentassem a morfologia necessária 
para a correta realização dos testes de angulação da embarcação, isto é, as áreas contêm feições batimétricas bem definidas.

A área 01, representada na Figura 7, é resultado de uma sondagem realizada em São Francisco do Sul, estado de Santa Catarina. Este levantamento foi executado em 2020 empregando um sistema multifeixe composto por um ecobatímetro modelo Sonic 2024 da marca R2 Sonic e um sistema inercial modelo ApogeeD da marca SBG, além de sensores auxiliares para medição da velocidade do som.

O Apogee-D é capaz de fornecer medições com as seguintes resoluções/precisões (SGB SYSTEM, 2016):

a) pitch e roll: $0,008^{\circ}$;

b) heading: $0,025^{\circ}$ (usando uma linha de base de 4 metros);

c) heave: $5 \mathrm{~cm}(2 \mathrm{~cm}$ pós-processado);

d) posicionamento RTK (Real Time Kinematic): $1 \mathrm{~cm}$ (horizontal).

Figura 7 - Área sondada em São Francisco do Sul.

LEVANTAMENTO BATIMÉTRICO MULTIFEIXE EM SÃO FRANCISCO DO SUL - SC

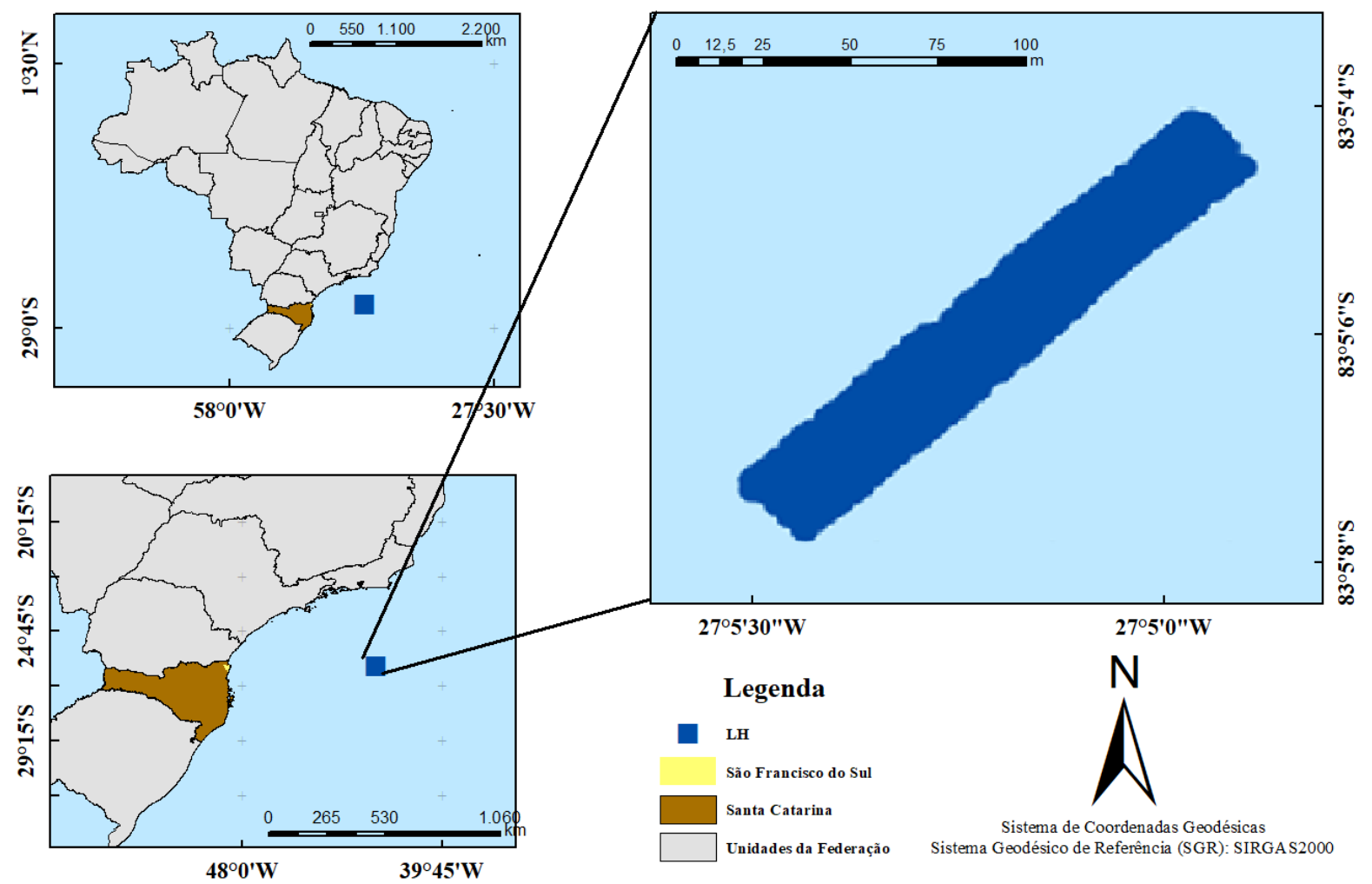

Fonte: Os autores (2021).

A segunda localização, área 02, apresentada na Figura 8, é proveniente de um levantamento batimétrico realizado em 2017, no Terminal Integrador Portuário Luiz Antônio Mesquita (TIPLAM), em Santos, no estado de São Paulo. O sistema utilizado na sondagem era composto por um ecobatímetro multifeixe modelo Sonic 2022 da marca R2 Sonic, contendo um sistema inercial, modelo I2NS Type I (Integrated Inertial Navigation System) da marca Applanix.

O I2NS é capaz de fornecer medições com as seguintes resoluções/precisões (R2 SONIC,2020):

a) pitch e roll: $0,01^{\circ}$;

b) heading: $0,01^{\circ}$ (usando uma linha de base de 4 metros);

c) heave: $5 \mathrm{~cm}(2 \mathrm{~cm}$ pós-processado);

d) posicionamento RTK: $1 \mathrm{~cm}$ (horizontal). 
Figura 8 - Área sondada em Santos -SP.

\section{LEVANTAMENTO BATIMÉTRICO MULTIFEIXE EM SANTOS - SP}

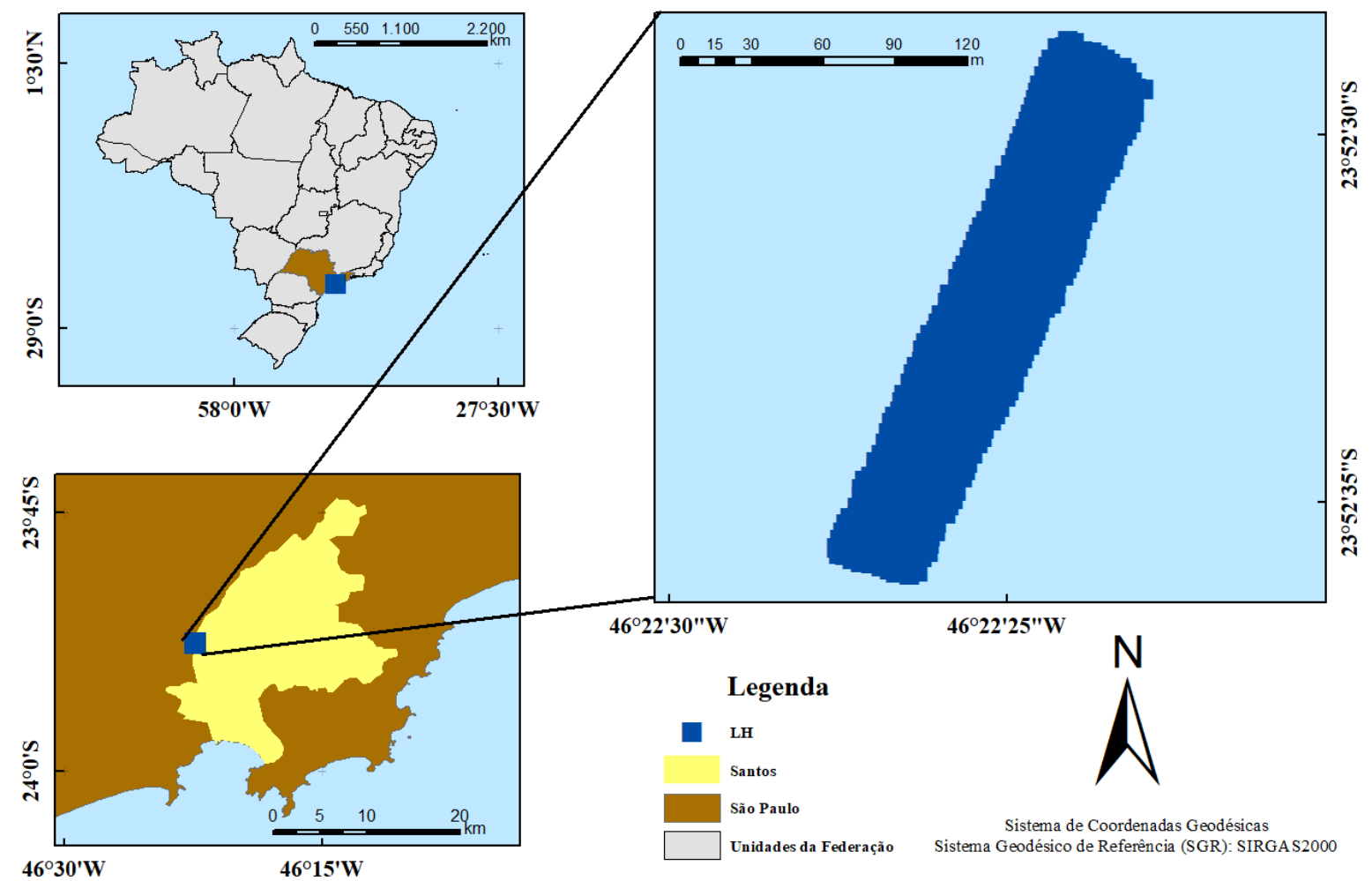

Fonte: Os autores (2021).

O planejamento dos levantamentos hidrográficos, assim como a coleta dos dados, seguiu as recomendações da NORMAM-25 (DHN, 2017). Foram executadas linhas de sondagem paralelas às isóbatas, evitando assim, falhas no recobrimento recomendado. Todos os procedimentos técnicos preconizados na norma foram seguidos, desde a instalação dos instrumentos (controle dimensional) até a coleta de perfis de velocidade do som.

De posse dos dados brutos, foi utilizado o software Hypack/Hysweep (HYPACK, 2020) para o processamento. Inicialmente foram aplicadas as correções de maré e de velocidade do som. Para cada caso, a maré foi observada por marégrafos instalados nas proximidades das áreas de estudos, o que permitiu que fossem aplicadas correções verticais às sondagens visando o cálculo das profundidades reduzidas, isto é, referenciadas ao nível de redução local.

As profundidades também foram compensadas dos efeitos causados pela variação do perfil de velocidade do som. Para isso, foram considerados no processamento os perfis de velocidade de propagação do som na água coletados durante o levantamento batimétrico. Posteriormente, prosseguiu-se com a conferência e compensação das medições instantâneas de velocidade e movimentos da embarcação (roll, pitch, heading $e$ heave). Por fim, efetuou-se a limpeza dos dados, isto é, a retirada de spikes com recurso à metodologia SODA (Spatial Outliers Detection Algorithm) (FERREIRA et al., 2019a; 2019b).

Realizado os devidos procedimentos, foi gerado uma superfície batimétrica (modelo batimétrico) para cada área de estudo, com recurso ao software Hypack (Hypack, 2020). Com base nesta superfície e no conhecimento prático dos relevos submersos, foram determinados os locais mais adequados para extração das seções batimétricas e posterior realização do patch test. Escolheu-se um relevo aproximadamente plano para calibração do roll e um relevo inclinado ou com uma feição bem definida para realização dos testes de pitch, heading e latência. Sabe-se que a seções batimétricas devem ser definidas perpendicular à direção de navegação para o teste de roll (seção transversal) e paralelas nos demais testes (seção longitudinal), sendo que para o teste de pitch e latência, idealmente deve-se definir a seção sobre a linha planejada, enquanto que para o teste de heading, deve-se buscar uma seção na faixa coberta por ambas as linhas de sondagem, conforme resume a Figura 9. 
Figura 9 - Escolha da seção para o processamento do patch test.

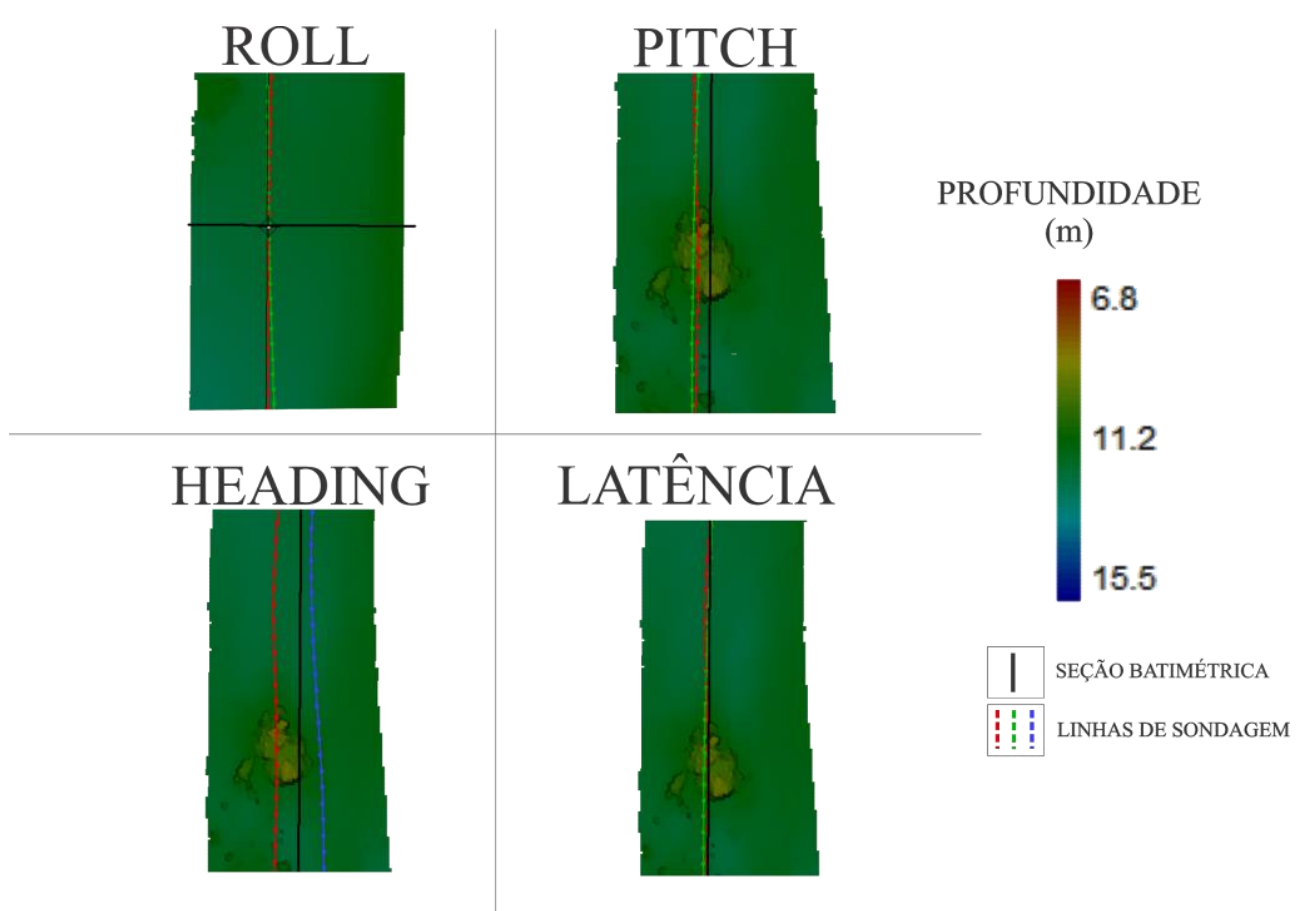

Fonte: Os autores (2021).

Definidas as seções procedeu-se com cálculo dos resíduos angulares e a latência, conforme as equações apresentadas na seção 2 e fluxograma apresentado na Figura 6. Nesta etapa foram realizados quatro testes, variando a sequência de processamento, conforme Tabela 1. A cada estimativa de um resíduo específico, os dados foram reprocessados, utilizando o software Hypack, de modo a evitar que o resíduo analisado viesse a comprometer as análises posteriores.

Tabela 1 -Sequência de processamento adotada neste estudo.

\begin{tabular}{l|c|c|c|c}
\hline & $\mathbf{1}^{\circ}$ & $\mathbf{2}^{\circ}$ & $\mathbf{3}^{\circ}$ & $\mathbf{4}^{\circ}$ \\
\hline Sequência 1 & Latência & Pitch & Heading & Heading \\
Sequência 2 & Latência & Roll & Pitch & Pitch \\
Sequência 3 & Latência & Roll & Heading & Heading \\
Sequência 4 & Latência & Pitch & Roll \\
\hline
\end{tabular}

Fonte: Os autores (2021).

A latência foi sempre o primeiro resíduo estimado, isso deveu-se, especialmente, ao fato dos sistemas multifeixe empregados serem integrados, além da latência influenciar demasiadamente as demais estimativas dos offsets residuais (IHO, 2005, DHN, 2017). O procedimento de calibração (patch test) é encontrado implementado em todos os softwares comerciais de coleta e processamento de dados batimétricos multifeixe, tais como o Hypack (HYPACK, 2020), Caris (TELEDYNE CARIS, 2020), Qinsy (QPS, 2014) e PDS 2000 (TELEDYNE, 2018). Mesmo assim, visando um maior controle dos resultados, neste trabalho optou-se por realizar os cálculos iterativos com auxílio do software R (R CORE TEAM, 2020), por meio de um algoritmo semiautomático. Em algumas fases do processamento, também foi empregado planilhas de cálculo e ferramentas de desenho assistido por computador.

O processo adotado no processamento analítico consistiu, basicamente, das seguintes etapas:

a) definir, com recurso às ferramentas de seleção disponíveis no Hypack, a seção batimétrica de um offset específico (roll, por exemplo);

b) exportar os dados em formato XYZ;

c) importar o arquivo XYZ no software R e construir os perfis da seção batimétrica;

d) mensurar os deslocamentos horizontais (pitch, heading e latência) ou verticais (roll), pelo menos dez vezes e em locais diferentes, conforme sugere Godin (1998); 
e) cálculo da média aritmética dos deslocamentos com posterior cálculo do offset residual analisado, empregando as equações apresentadas na seção 2;

f) aplicação do offset residual e plotagem dos novos perfis batimétricos;

g) verificação do encaixe dos perfis e correção final dos dados batimétricos.

Após a aplicação do offset residual encontrado na primeira iteração já é possível verificar visualmente uma melhora no encaixe entre os perfis verticais da seção batimétrica analisada. Caso não haja um "encaixe perfeito", o que de fato é esperado na primeira iteração, deve-se refazer todo o processo (processamento iterativo). Neste trabalho, optou-se por adotar como tolerância o valor da Incerteza Vertical Total (IVT) correspondente a Ordem Exclusiva prevista na sexta edição da S-44 (IHO, 2020), isto é, considera-se um "encaixe perfeito" quando os maiores deslocamentos observados entre os perfis forem iguais ou inferiores a esta tolerância. No cálculo da IVT empregou-se a profundidade média da seção batimétrica analisada (adotouse a média de apenas um dos perfis - escolhido aleatoriamente). Findado a análise do primeiro resíduo (roll, por exemplo), corrige-se os dados e efetua-se a análise do próximo offset (pitch, por exemplo). Conforme discutido, esta análise foi realizada nas duas áreas de estudo, variando a sequência de processamento quatro vezes, conforme Tabela 1.

Outra forma de se efetuar o processamento do patch test, comumente empregada pelos softwares comerciais e computacionalmente mais simples, consiste em, definida a seção batimétrica, aplicar diferentes offsets angulares aos dados batimétricos $\left(-10^{\circ}\right.$ à $10^{\circ}$, variando de $1^{\circ}$ em $1^{\circ}$, por exemplo) e, para cada offset, calcular o RMS das diferenças entre os dados de profundidade. Esse processo gera um gráfico (RMS $\mathrm{x}$ Resíduo) que auxilia na definição do offset residual. Um o gráfico cuja a forma se assemelhe a uma plotagem de $\mathrm{f}(\mathrm{x})=\mathrm{x}^{2}$ é considerado ideal e o valor do offset residual adotado é geralmente o valor que apresenta o menor RMS. A Figura 10 a seguir ilustra o procedimento gráfico.

Figura 10 -Exemplificação do ajuste entre os perfis batimétricos e o gráfico (RMS x offset residual) ambos gerados no software Hypack.
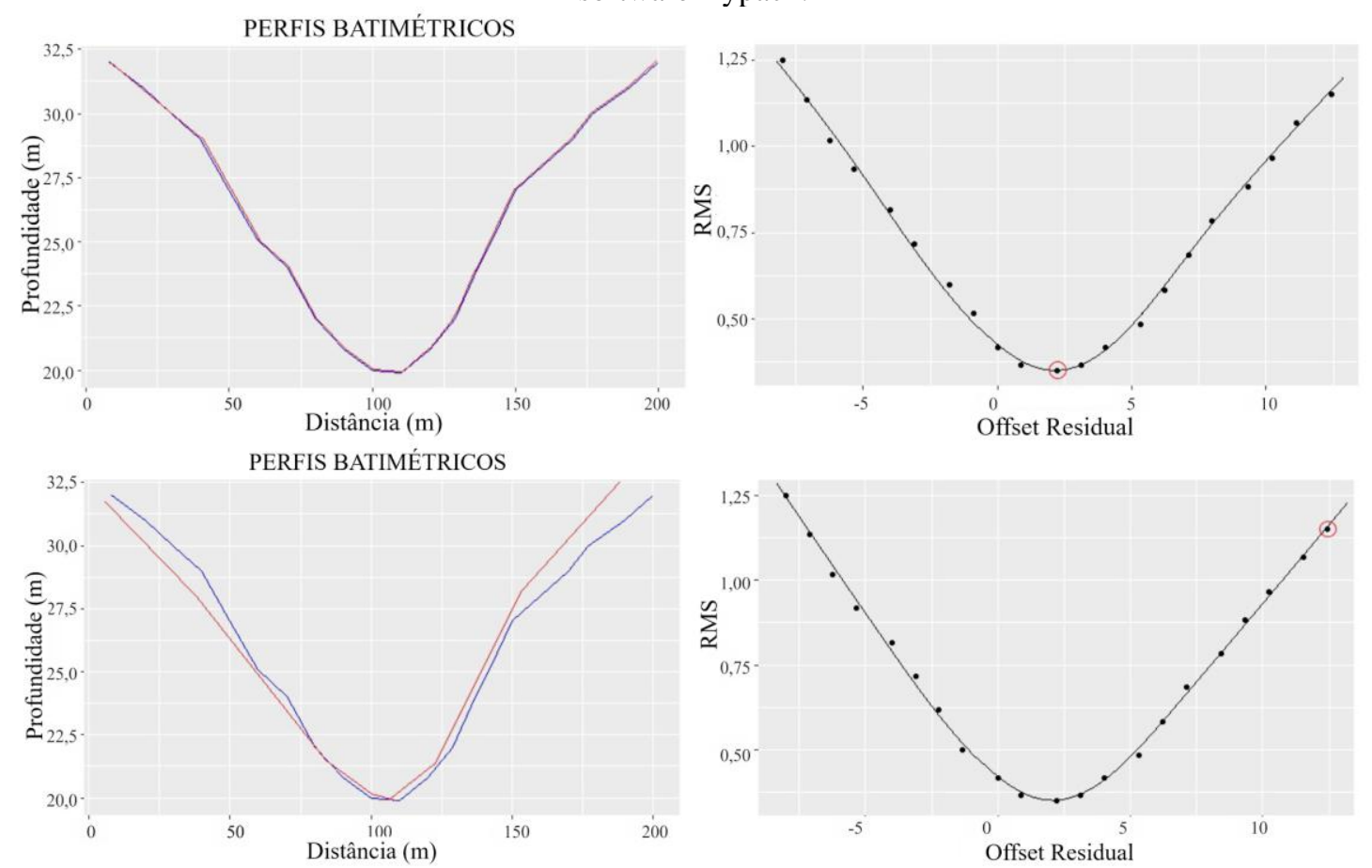

Fonte: Os autores (2021).

Neste estudo, este procedimento também foi realizado visando comparar os resultados. Empregou-se nesta etapa também os softwares R e Hypack (HYPACK, 2020; R CORE TEAM, 2020), além de ferramentas de desenho assistido por computador. Após obtenção do offset residual pelo método gráfico, o mesmo foi aplicado aos dados, com posterior recálculo do offset, objetivando obter, agora, um valor nulo. Em casos contrários, a análise foi refeita. Este processo também deve ser iterativo.

Como sabido, dados batimétricos adquiridos por sistemas multifeixe podem apresentar uma 
determinada amplitude vertical, evidenciado quando se traça o perfil (ou perfis) da seção batimétrica, conforme é ilustrado na Figura 11.

Figura 11 - Exemplo de seção batimétrica e respectivo perfil (de uma única varredura multifeixe) ilustrando a amplitude vertical das profundidades. Na figura à direita, cada ponto corresponde a uma profundidade calculada.
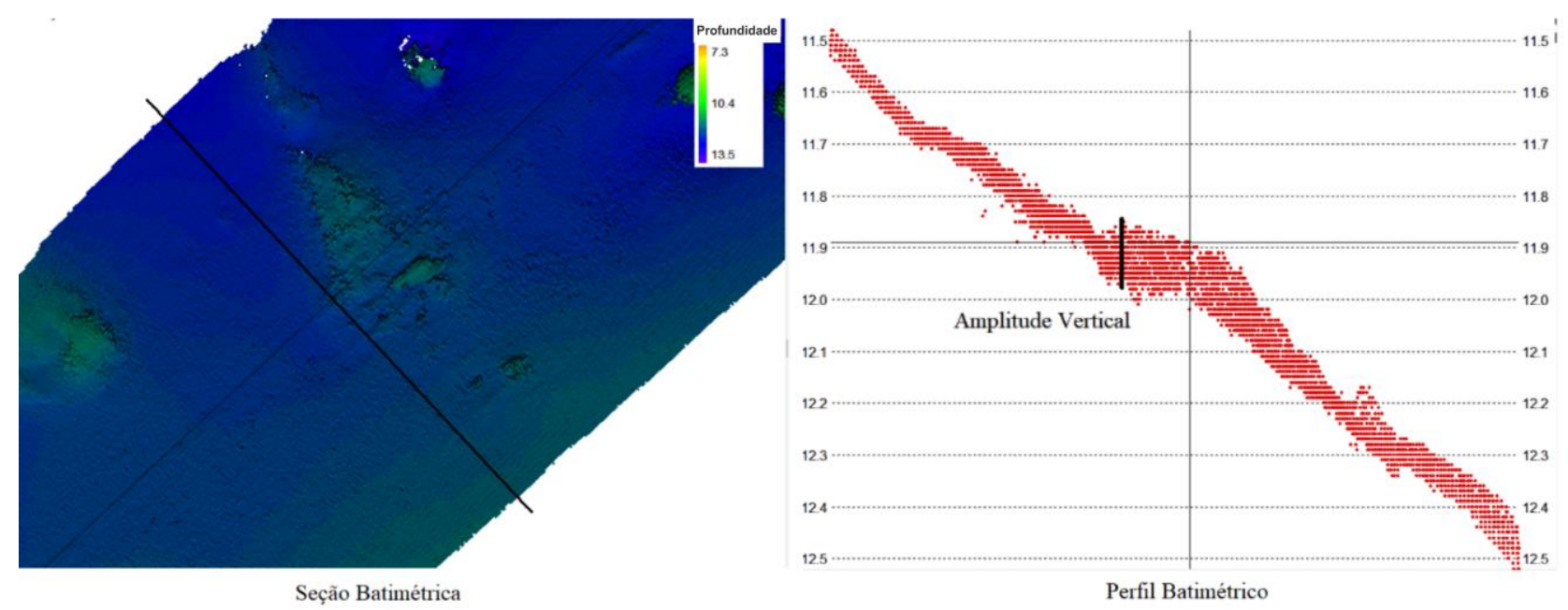

Fonte: Os autores (2021).

Essa amplitude vertical das profundidades não se configura como ruído ou incerteza vertical dos dados e pode depender, entre outros, do relevo submerso e do setor angular da varredura multifeixe. Evidencia-se que, em alguns casos, o nível de dispersão vertical existente nos dados impossibilitou as análises, havendo, em alguns casos, trechos em que a observância e a busca por deslocamentos eram impraticáveis. Nestes casos, optou-se por extrair uma linha de tendência dos perfis batimétricos analisados e emprega-las nos processamentos. Assim, toda a análise relacionada a obtenção dos offsets residuais e a verificação do encaixe vertical, foram realizadas por meio dos perfis das linhas de tendência (Figura 12).

Figura 12 - À esquerda, perfis batimétricos com aparente offset residual no roll e, à direita, os perfis após a aplicação do valor residual e a linha de tendência.

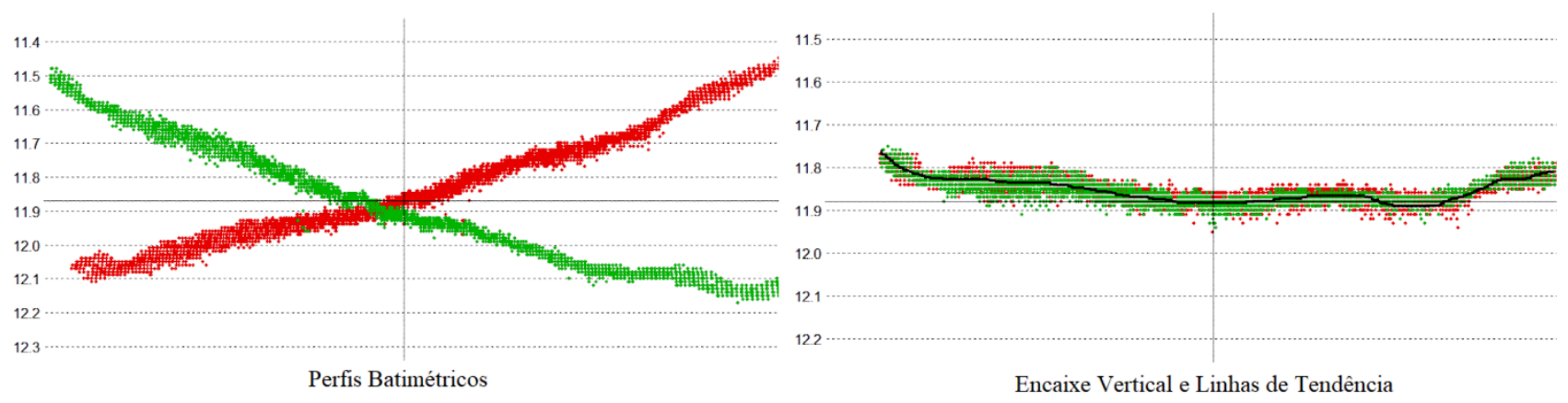

Fonte: Os autores (2021).

Quando necessário, a linha de tendência dos dados foi extraída empregando a Média Espacial Móvel. A média espacial móvel tem por objetivo identificar padrões e evidenciar tendências de dados espaciais, possuindo uma representação mais suave em relação aos dados originais, ou seja, a variabilidade espacial dos dados diminui (BERTOLLA, 2015). Segundo Santos e Raia Jr. (2006), esta média é um dos indicadores mais utilizados para prever a tendência de dados espaciais.

\section{RESULTADOS E DISCUSSÕES}

A tolerância adotada para o processamento do patch test neste estudo consistiu na IVT referente a ordem exclusiva presente na sexta edição da S-44, que deverá entrar em vigor em 2021. No que se refere às linhas de tendência, empregadas em algumas análises, elas foram geradas com recurso ao cálculo da Média Espacial Móvel. 
Na Tabela 2 são apresentados os resultados dos quatro testes realizados através do método analítico para as localidades Área 01 e Área 02.

Tabela 2 - Resultados do patch test executados para a Área 01 e Área 02 (método analítico).

\begin{tabular}{|c|c|c|c|c|c|c|}
\hline & Offset residual & Teste 1 & Teste 2 & Teste 3 & Teste 4 & Média \\
\hline \multirow{4}{*}{ Área 01} & Latência (s) & 0 & 0 & 0 & 0 & 0 \\
\hline & Pitch $\left({ }^{\circ}\right)$ & $-0,45$ & $-0,50$ & $-0,40$ & $-0,45$ & $-0,45$ \\
\hline & Roll (º) & $-0,60$ & $-0,75$ & $-0,75$ & $-0,80$ & $-0,73$ \\
\hline & Heading $\left({ }^{\circ}\right)$ & 1,74 & 2,00 & 1,50 & 1,51 & 1,69 \\
\hline \multirow{4}{*}{ Área 02} & Latência (s) & 0 & 0 & 0 & 0 & 0 \\
\hline & Pitch $\left({ }^{\circ}\right)$ & 0,50 & 0,40 & 0,30 & 0,50 & 0,43 \\
\hline & Roll ( $\left.{ }^{\circ}\right)$ & 0,30 & 0,30 & 0,30 & 0,40 & 0,25 \\
\hline & Heading $\left({ }^{\circ}\right)$ & 1,50 & 0,50 & 1,50 & 1,45 & 1,24 \\
\hline
\end{tabular}

Fonte: Os autores (2021).

Como pode ser observado na Tabela 2, em todos os casos a latência do sistema de sondagem foi nula, indicando não haver qualquer atraso entre o sistema de posicionamento e o ecobatímetro multifeixe. De fato, esse resultado já era esperado devido as características técnicas do sistema.

$\mathrm{Na}$ Área $01, \mathrm{o}$ offset residual em pitch variou entre $-0,50^{\circ}$ e $-0,40^{\circ}$, sendo o valor médio igual a $-0,45^{\circ}$, mesmo resultado dos testes 1 e 4, em que o processamento do pitch é realizado logo após a finalização do teste de latência. Na Área 02, de modo análogo, os testes 1 e 4 apresentaram os mesmos resultados, enquanto que nas sequências adotadas para o teste 2 e 3 , os resultados foram, respectivamente, $0,40^{\circ}$ e $0,30^{\circ}$. Os testes para obter o resíduo em roll apresentaram, para a Área 01 , resultados variando de $-0,60^{\circ}$ à $-0,80^{\circ}$. Os testes 2 e 3 apresentaram valores idênticos, haja visto que nestes casos o roll é analisado logo após a latência. Para a Área 02 , os testes 1,2 e 3 apresentaram como resultado o valor residual de $0,30^{\circ}$, enquanto o teste 04 gerou um roll offset de $0,40^{\circ}$. Por fim, o heading foi analisado. Na Área 01 todos os valores residuais no ângulo de proa foram diferentes. Obteve-se um valor máximo de $2,00^{\circ}$ e um mínimo de $1,50^{\circ}$. Na Área 02 , os testes 1 e 3 geraram o um heading offset de $1,50^{\circ}$, enquanto os testes 2 e 4 resultaram, respectivamente, em $0,50^{\circ}$ e $1,45^{\circ}$.

A seguir são ilustrados, de maneira mais elucidativa, os resultados.

Figura 13 - Gráficos dos resultados do patch test executados para a Área 01 e Área 02 (método analítico).
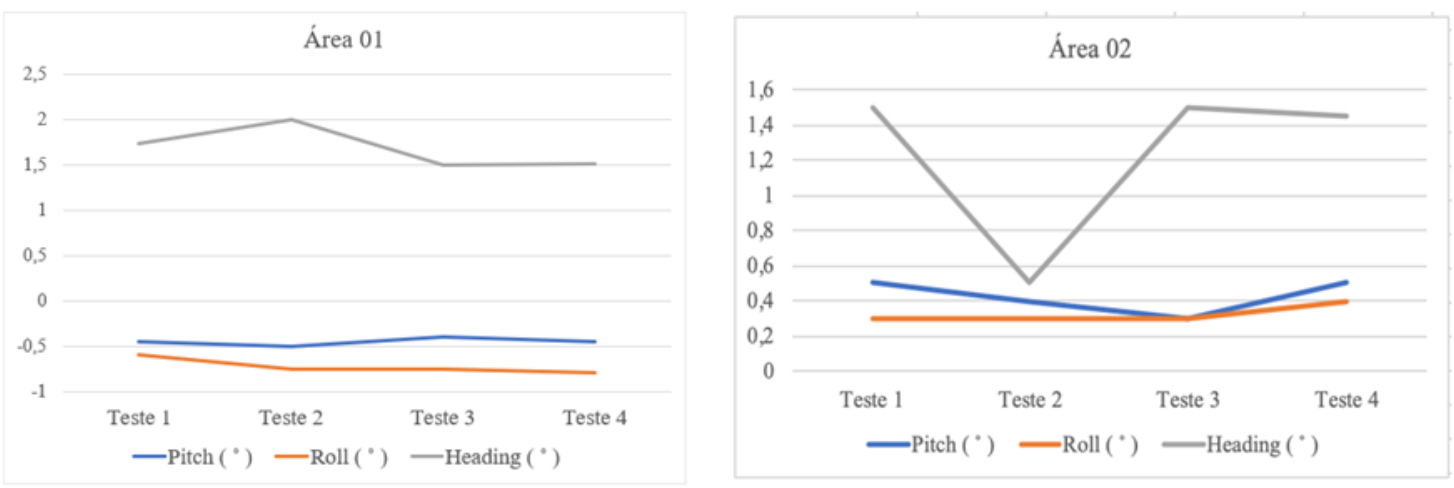

Fonte: Os autores (2021).

Pode-se notar que, no geral, a sequência de processamento, assim como a escolha da seção batimétrica, pode influenciar os resultados. Em alguns casos, como a estimativa do resíduo em heading no teste 2 para a Área 02, a discrepância em relação aos demais resultados é nítida. Em todos os casos, após findado o patch test, procedeu-se com a correção dos dados batimétricos por meio do software Hypack com posterior plotagem dos perfis de algumas seções batimétricas, especificamente, sobre feições submersas com relevo variado. Tanto para a Área 01, quanto para a Área 02, o teste 04, isto é, a sequência: Latência, pitch, roll e heading, forneceram os resultados que apresentaram os melhores encaixes verticais, muito embora os testes 1 e 3 tenham resultado em encaixes verticais similares.

Como discutido, o processamento do patch test, nas quatro sequências analisadas, também foi conduzido por meio gráfico. Os resultados obtidos para as Área 01 e Área 02 são apresentados na sequência. 
Inicialmente foi aplicado o teste de latência (Figura 14).

Figura 14 - Resultados gráficos para o teste de latência da Área 01 e Área 02.

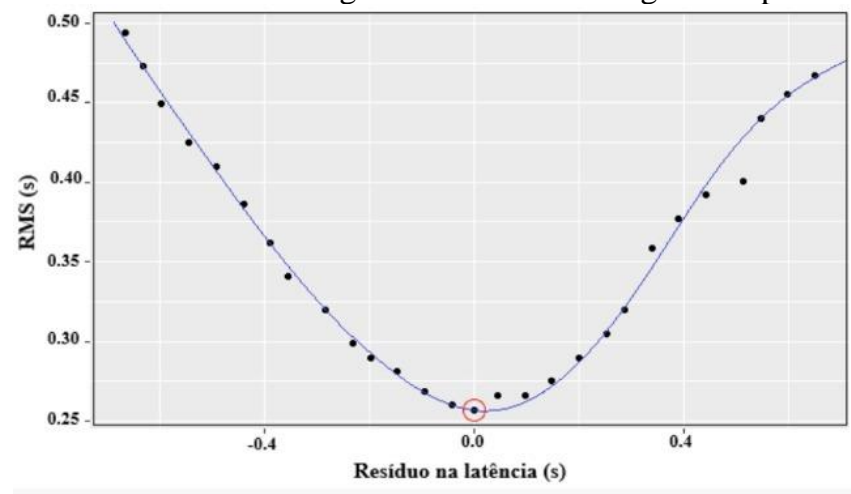

ÁREA 01

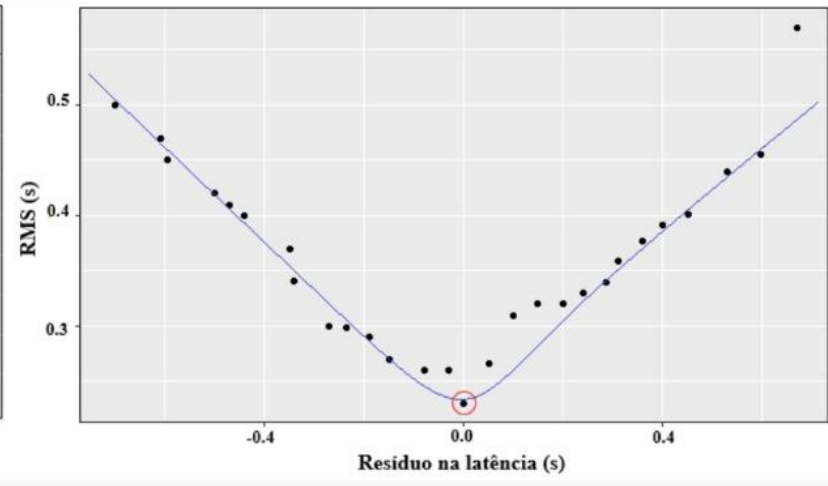

ÁREA 02

Fonte: Os autores (2021).

Como pode ser observado, assim como para o método analítico, o método gráfico resultou numa latência nula, como esperado. Posteriormente, prosseguiu-se com as demais estimativas (Figuras 15 e 16).

Figura 15 - Resultados gráficos do patch test executados para a Área 01.

TESTE 1
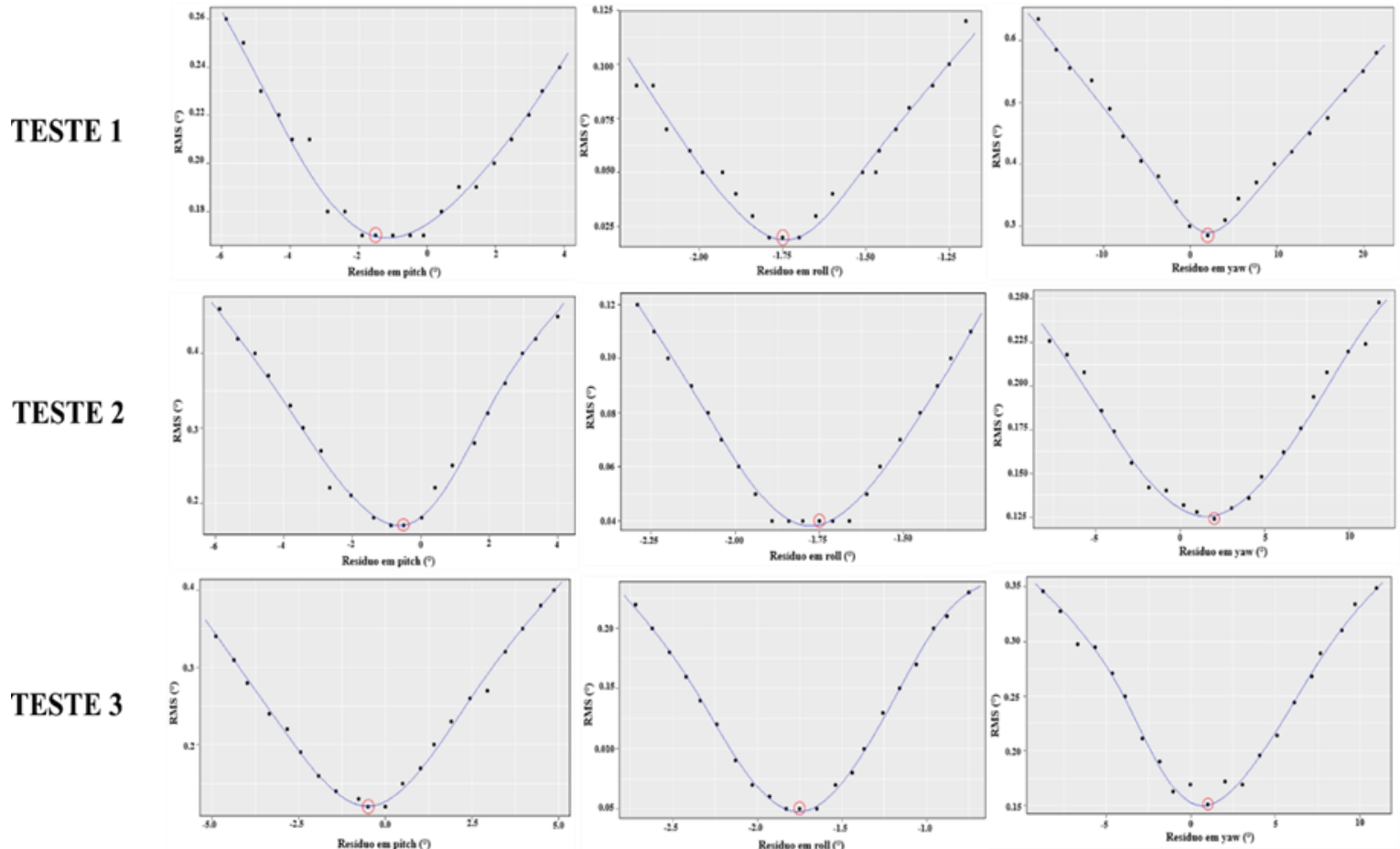

TESTE 3
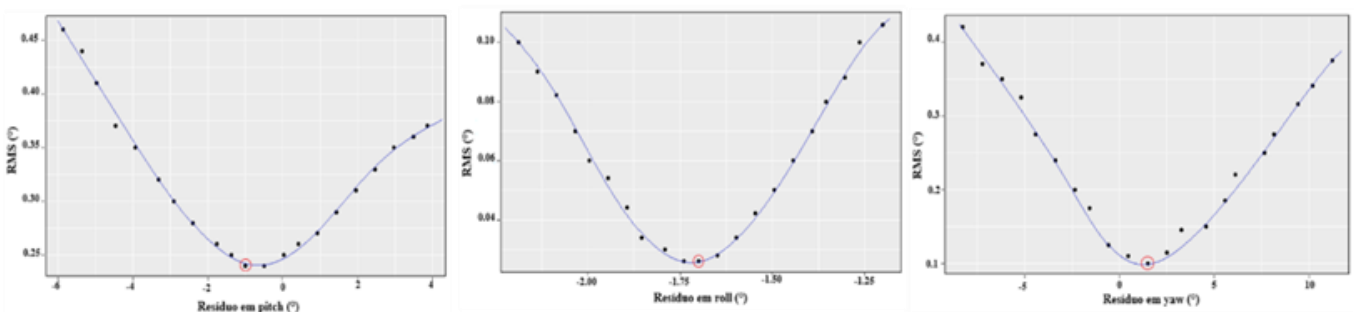

Fonte: Os autores (2021). 
Figura 16 - Resultados gráficos do patch test executados para a Área 02.

TESTE 1
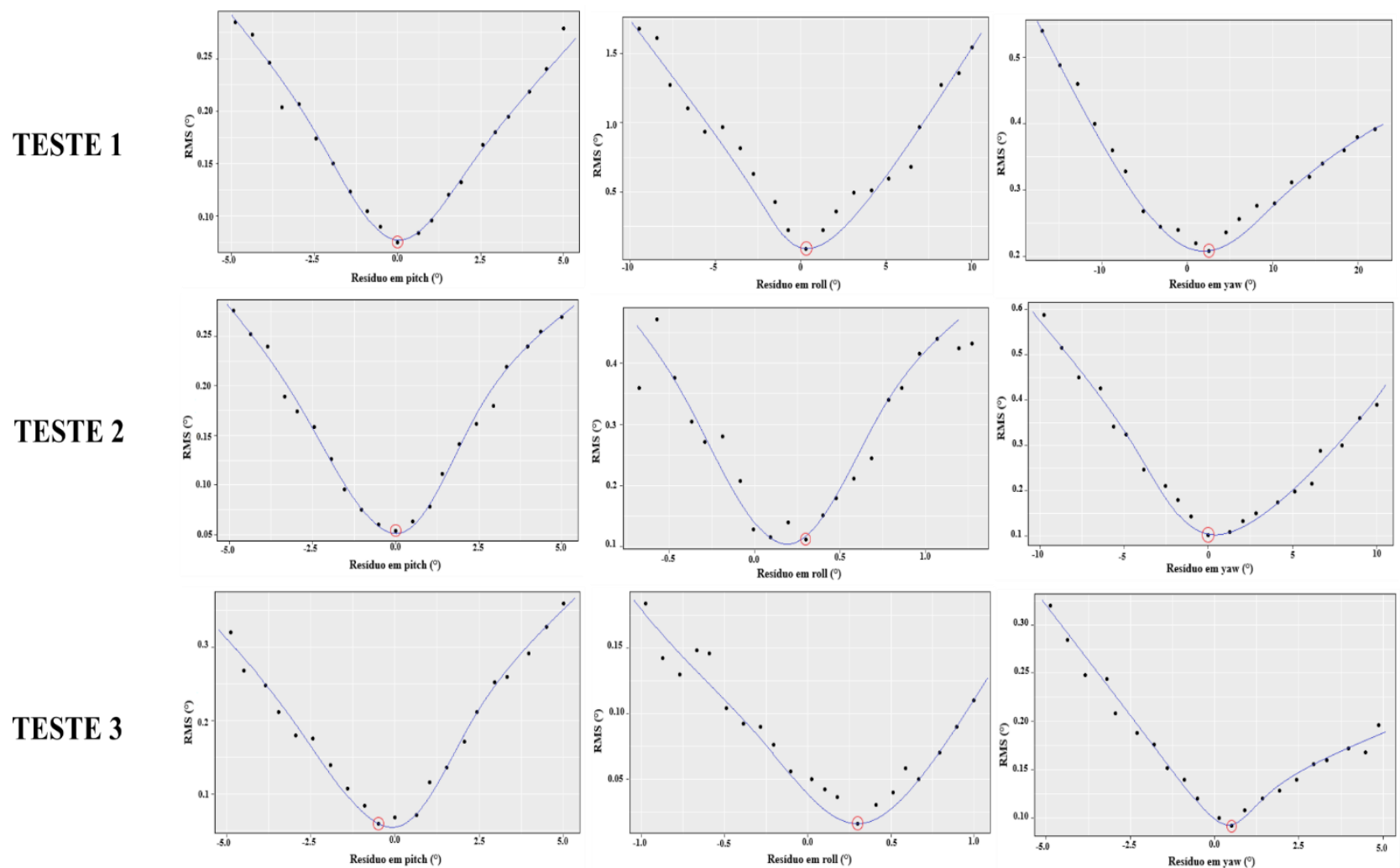

TESTE 4
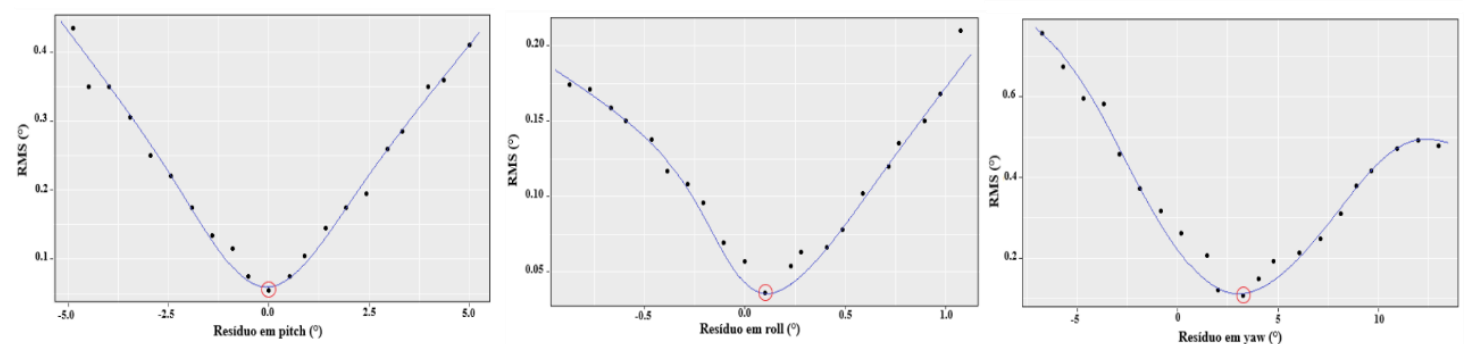

Fonte: Os autores (2021).

Neste estudo, optou-se por adotar como resultado para o offset residual, o valor correspondente ao menor RMS. Todavia, deve-se atentar que nem sempre o menor RMS resultará num melhor encaixe vertical dos feixes. Na Tabela 3 e Figura 16 são sumarizados os resultados dos quatro testes realizados através do método gráfico para as localidades Área 01 e Área 02.

Tabela 3 - Resultados do patch test executados para a Área 01 e Área 02 (método gráfico).

\begin{tabular}{|c|c|c|c|c|c|c|}
\hline & Offset residual & Teste 1 & Teste 2 & Teste 3 & Teste 4 & Média \\
\hline \multirow{4}{*}{ Área 01} & Latência (s) & 0 & 0 & 0 & 0 & 0 \\
\hline & Pitch $\left({ }^{\circ}\right)$ & $-1,50$ & $-0,50$ & $-0,50$ & $-1,00$ & $-0,88$ \\
\hline & Roll ( $\left.{ }^{\circ}\right)$ & $-1,75$ & $-1,75$ & $-1,75$ & $-1,70$ & $-1,74$ \\
\hline & Heading $\left({ }^{\circ}\right)$ & 2,00 & 2,00 & 1,00 & 1,50 & 1,63 \\
\hline \multirow{4}{*}{ Área 02} & Latência (s) & 0 & 0 & 0 & 0 & 0 \\
\hline & Pitch $\left({ }^{\circ}\right)$ & 0,00 & 0,00 & $-0,50$ & 0,00 & $-0,13$ \\
\hline & Roll ( $\left.{ }^{\circ}\right)$ & 0,30 & 0,30 & 0,30 & 0,10 & 0,25 \\
\hline & Heading $\left({ }^{\circ}\right)$ & 2,50 & 0,00 & $-0,50$ & 2,00 & 1,25 \\
\hline
\end{tabular}

Fonte: Os autores (2021).

Como pode ser observado na Tabela 3, na Área 01 o offset residual apresentou uma variação em pitch entre $-0,50^{\circ}$ e $-1,50$, com um valor médio igual a $-0,88^{\circ}$. Na Área 02 , de modo inesperado, os resíduos em pitch foram nulos em três testes. Era esperado que nos testes 1 e 4, os resultados fossem idênticos, porém tal fato não ocorreu para a Área 01, o que pode ser explicado pela subjetividade do método gráfico, aliado ao emprego de seções diferentes. Os resíduos em roll variaram na Área 01 , apenas $-0,05^{\circ}$, obtendo-se valores idênticos para os testes 1,2 e 3. Para Área 02 , os resultados foram similares, exceto pela maior variação $\left(0,20^{\circ}\right)$. Por fim, 
o heading apresentou uma variação de até $1,00^{\circ}$ para a Área 01 e $2,50^{\circ}$ para a Área 02 . Os resultados são melhor elucidados na Figura 17.

Figura 17 - Gráficos dos resultados do patch test executados para a Área 01 e Área 02 (método gráfico).
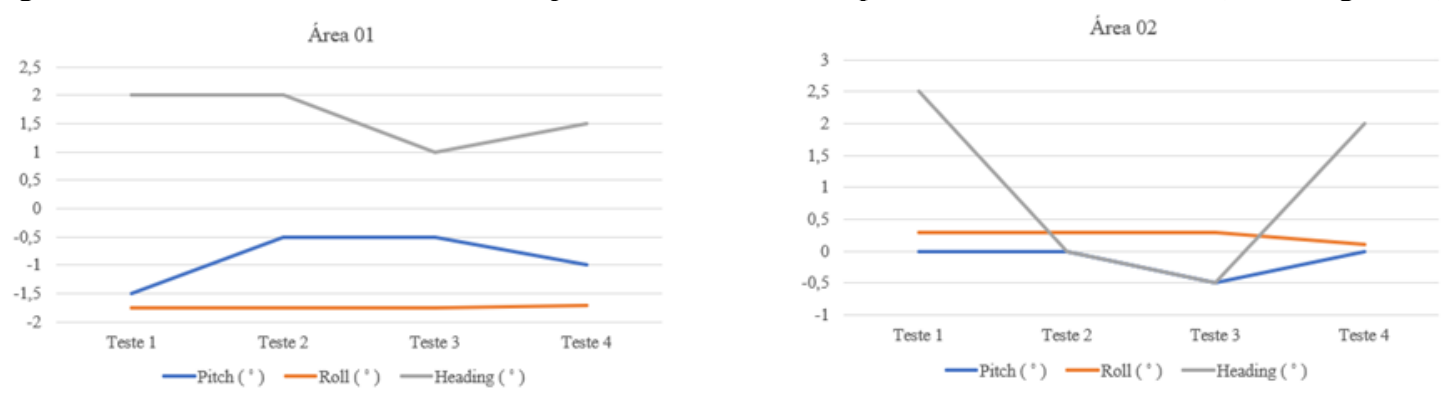

Fonte: Os autores (2021).

De modo similar ao ocorrido para a abordagem analítica, na Área 01 e Área 02, o offsets em pitch e roll mostraram certa tendência, enquanto o heading mostrou-se novamente uma variável complexa para estimar. Ainda sobre o heading, os testes 2 e 3 da Área 02 resultaram em valores não condizentes com o esperado. Os valores encontrados, em todos os casos, foram empregados para corrigir os dados batimétricos, permitindo visualizar os encaixes verticais de algumas seções batimétricas. Embora seja uma análise subjetiva, é de fato efetiva e empregada na prática hidrográfica. No caso da abordagem gráfica, os encaixes verticais não se mostraram tão "perfeitos" quanto aqueles resultantes da abordagem analítica. Todavia, as sequências 1 e 4 , apresentaram resultados satisfatórios. Um comparativo entre as abordagens é ilustrado a seguir (Figura 18).

Figura 18 - Gráficos comparativos dos resultados obtidos pelas abordagens analítica e gráfica.
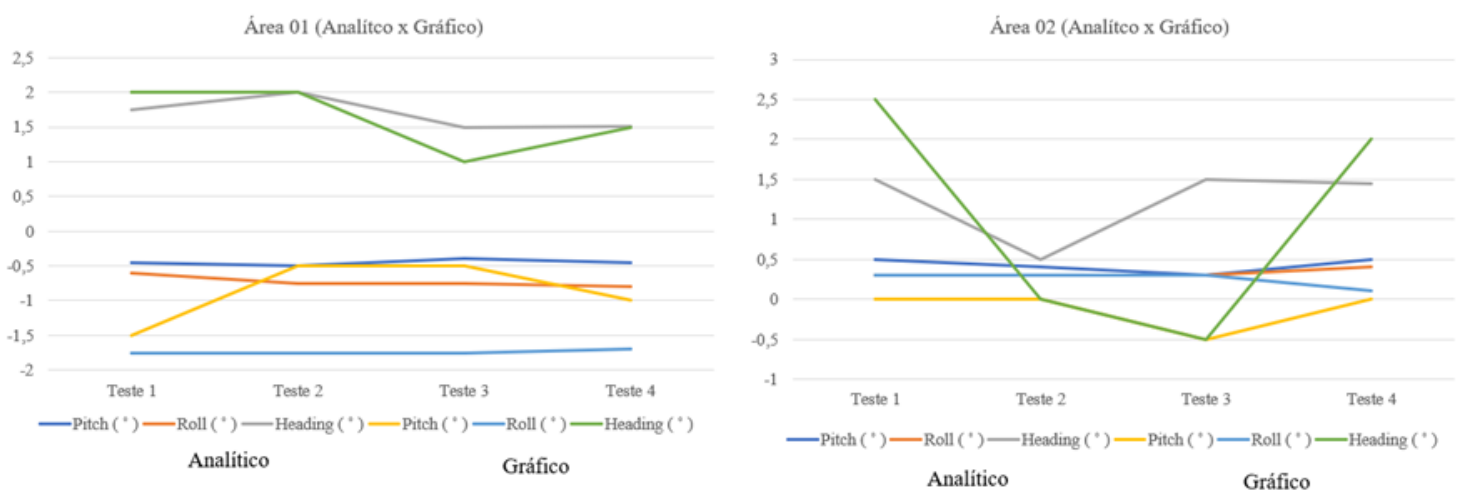

Fonte: Os autores (2021).

Em termos comparativos, os métodos apresentaram valores médios, de um modo geral, diferentes. Na Área 01, o offset em roll estimado pelo método gráfico apresentou uma maior discrepância em relação à abordagem analítica, embora tenha apresentado resultados equivalentes em todos os testes. Na Área 02, os resultados apresentaram maiores discordâncias, especialmente para o heading e pitch offsets. Apenas o teste 4 apresentou resultados similares para ambos os parâmetros. Conforme afirma Godin (1998), todos os resíduos que apresentem valores maiores que $1^{\circ}$, possivelmente estão com problemas de alinhamento e necessitam terem a sua instalação e controle dimensional revisados. Assim, pode-se constatar também que os sistemas multifeixe empregados neste estudo apresentam problemas de alinhamento das antenas GNSS utilizadas na estimativa do heading. Por fim, conclui-se que o sequenciamento adotado no processamento do patch test conduz a resultados diferentes. Embora este estudo tenha apontado que o teste 4 associado à abordagem analítica possa apresentar melhores resultados, o analista deve sempre observar a metodologia e sequenciamento adotado pelo software utilizado. 


\section{CONCLUSÕES}

De acordo com a metodologia apresentada neste trabalho, foi realizada a verificação da sequência de processamento do patch test utilizando os métodos, aqui chamados de, analítico e gráfico em duas áreas de estudo distintas. Em levantamentos hidrográficos com ecobatímetros multifeixe, a execução do patch test se faz essencial, uma vez que através deste é possível identificar e quantificar os parâmetros angulares residuais em roll, pitch, heave e latência (delay time). Embora já existam no mercado ferramentas que automatizam a avaliação dos resíduos angulares, os procedimentos descritos neste documento podem ajudar aqueles que não estão equipados com essas ferramentas, além de ajudar no entendimento da calibração de um modo geral.

Uma vez que todos os desvios residuais são correlacionados e contribuem para o cálculo da profundidade e posição, os resíduos precisam ser isolados antes de serem detectados, quantificados e corrigidos sistematicamente em uma sequência ordenada. De fato, pôde-se constatar neste estudo que o método analítico associado ao sequenciamento: Latência, pitch, roll e heading, fornece os melhores resultados, isto é, encaixes verticais "perfeitos". No entanto, o interessado em realizar a calibração devem atentar que a maioria dos pacotes hidrográficos valem-se do método gráfico, devido a facilidade computacional e, assim, o sequenciamento adotado pela ferramenta empregada no processamento deve ser observada.

Verifica-se também que grandes desvios angulares, isto é, superiores a $1^{\circ}$, encontrados no patch test, sugerem problemas de instalação, portanto, os sistemas multifeixes utilizados neste estudo precisam sofrer uma revisão de alinhamento, pelo menos, das antenas GNSS (heading).

Como recomendação para complementação deste trabalho sugere-se o desenvolvimento de uma ferramenta totalmente automatizada para a execução do patch test de modo analítico, com estimativa do RMS entre as profundidades dos perfis analisados e empregando os quatros sequenciamento sugeridos, permitindo ao analista julgar qual sequência apresenta maior coerência. Sugere-se também, que esta pesquisa seja replicada para sonares interferométricos e que estudos a cerca da qualidade posicional e da diferença entre os volumes calculados com diferentes sequências de procedimento do patch test seja realizado.

\section{Agradecimentos}

Os autores agradecem ao GEPLH (Grupo de Estudo e Pesquisa em Levantamentos Hidrográficos) da Universidade Federal de Viçosa e à empresa A2 Marine Solutions pelo apoio e contribuição no desenvolvimento desta pesquisa.

\section{Contribuição dos autores}

As contribuições dos autores no desenvolvimento deste trabalho são: Conceptualização, curadoria dos dados, investigação, metodologia, redação - minuta inicial e redação - revisão e edição, Italo Oliveira Ferreira; visualização e redação - revisão e edição, Laura Coelho de Andrade; visualização e redação - revisão e edição, Felipe Mesquita dos Santos; visualização e redação - revisão e edição, Larissa Messias de Souza.

\section{Conflitos de interesse}

Os autores declaram que não há conflito de interesse.

\section{Referências}

BERTOlla, J. M. Técnicas de análise de dados distribuídos em áreas. 46f. Dissertação (Mestrado) Universidade Estadual Paulista Júlio de Mesquita Filho, Instituto de Biociências, Botucatu, 2015.

BATTISTA, T. A.; STECHER, M. L. Data Acquisition \& Processing Report. Type of Survey: Benthic Habitat and Hydrographic Project, 2007.

CLARKE, J. E. H. A reassessment of vessel coordinate systems: what is it that we are really aligning? In: US Hydrographic Conference. 12p. 2003. 
CLARKE, J. E . H. Imaging and Mapping II: Submarine Acoustic Imaging Methods. Notes of classes. Ocean Mapping Group. University of New Brunswick. 2014.

DIRETORIA DE HIDROGRAFIA E NAVEGAÇÃO (DHN). NORMAM 25: Normas da Autoridade Marítima para Levantamentos Hidrográficos. Marinha do Brasil, Brasil, 94 p., 2017.

EISENBERG, J.; DAVIDSON, M.; BEAUDION, J.; BRODET, S. Rethinking the patch test for phase measuring bathymetric sonars. University of New Hampshire. Scholars Repository .2011. Disponível em <https://scholars.unh.edu/ccom/809/>. Acesso em 20 mar. 2020.

FERREIRA, Í. O.; RODRIGUES, D. D.; NETO, A. A.; MONTEIRO, C. S. Modelo de incerteza para sondadores de feixe simples. Revista Brasileira de Cartografia, v. 68, n 5. 2016.

FERREIRA, I. O.; SANTOS, A. D. P. D.;OLIVEIRA, J. C. D.; MEDEIROS, N. D. G.; EMILIANO, P. C. Spatial Outliers Detection Algorithm (SODA) applied to multibeam bathymetric data processing. Boletim de Ciências Geodésicas, v. 25, n. 4, 2019 a.

FERREIRA, I. O.; SANTOS, A. D. P. D.;OlIVEIRA, J. C. D.; MEDEIROS, N. D. G.; EMILIANO, P. C. Robust Methodology For Detection Of Spikes In Multibeam Echo Sounder Data. Boletim de Ciências Geodésicas, v. 25, n. 3, 2019b.

GUERIOT, D.; CHEDRU, J.; DANIEL, S.; MAILLARD, E. The patch test: a comprehensive calibration tool for multibeam echosounders. In: OCEANS 2000 MTS/IEEE Conference and Exhibition. v.3, pp. 1655-1661. 2000.

GODIN, A. The Calibration of Shallow Water Multibeam EchoSounding Systems. M. Eng. report, Department of Geodesy and Geomatics Engineering, Technical Report n. 190, University of New Brunswick, Fredericton, New Brunswick, Canada, 182p., 1998.

HYPACK, Inc. Hypack - Hydrographic Survey Software User Manual. Middletown, USA, 1784p., 2020.

INTERNATIONAL HYDROGRAPHIC ORGANIZATION (IHO). C-13: IHO Manual on Hydrography. Mônaco: International Hydrographic Bureau, 540p., 2005.

INTERNATIONAL HYDROGRAPHIC ORGANIZATION (IHO). S-44: IHO Standards for Hydrographic Surveys. Special Publication n. 44-5th. Mônaco: International Hydrographic Bureau, 36p., 2008.

INTERNATIONAL HYDROGRAPHIC ORGANIZATION (IHO). S-44: IHO Standards for Hydrographic Surveys. 6th Edition. IHO publication Nn.44,2020.

INSTITUTO HIDROGRÁFICO. Especificação Técnica para Produção de cartografia hidrográfica. Marinha Portuguesa, Lisboa, Portugal, v 0.0, 24p., 2009.

LEKKERKERK, H. J.; VELDEN, R. V.; HAYCOCK, T.; JANSEN, P.; VRIES, R. D.; WAALWIJK, P. V., et al. Handbook of Offshore Surveying Volume One: Preparation \& Positioning. London: Clarkson Research Service Limited.2006.

LAND INFORMATION NEW ZEALAND (LINZ). Contract Specifications for Hydrographic Surveys. New Zealand Hydrographic Authority, v. 1.2, 111p., 2010.

MALEIKA, W. The influence of the grid resolution on the accuracy of the digital terrain model used in seabed modeling. Marine Geophysical Research, v. 36, n. 1, p. 35-44, 2015.

MANN, R. Field calibration procedures for multibeam sonar systems. ARMY TOPOGRAPHIC ENGINEERING CENTER ALEXANDRIA VA, 1998.

NARDEZ, N.N.; KRUEGER, C. P.; SOUZA, A. V.; DALMOLIN, Q. Determinação dos afastamentos (offsets) entre sensores numa embarcação hidrográfica. Revista Brasileira de Cartografia, v.68, n.5, 2016.

NATIONAL OCEANIC AND ATMOSPHERIC ADMINISTRATION (NOAA). Field Procedures Manual. Office of Coast Survey, 2011.

PEIRIÇO, A. C. M.; MARREIROS, J. P.R. Levantamento hidrográfico para a extensão da Plataforma Continental-LH3. Instituto Hidrográfico, 2005. 
QPS, QINSY. Quality Positioning Services Qinsy 9 - Survey and Navigation . V.9.1.1. 2014. Disponível em: < http://www.qps.nl/display/qinsy/laser> . Acesso em 20 de abril de 2020.

R CORE TEAM. R: A language and environment for statistical computing. Vienna, Austria: R Foundation for Statistical Computing.2020.

R2 SONIC. R2Sonic I2NS Integrated Inertial Navigation System Specifications.I2NS Type I.2020. Disponível em: $\quad$ https://www.r2sonic.com/wp-content/uploads/2020/03/L2NS-spec-sheet-A4-022020.pdf > . Acesso em 20 de abril de 2020.

R2 SONIC. R2Sonic LLC Multibeam Training. Multibeam Calibration: The patch teste. 2017.

SANTOS, L.; RAIA JR, A. A. Análise espacial de dados geográficos: a utilização da Exploratory Spatial Data Analysis - ESDA para identificação de áreas críticas de acidentes de trânsito no município de São Carlos (SP). V.18, n., p.97-107. Sociedade \& Natureza, Uberlândia, 2006.

SGB SYSTEM. Apogee Marine Series. Ultimate Accuracy Mems - Inertial Navigation System.2016. Disponível em: $<\mathrm{http}: / / \mathrm{a} 2 \mathrm{marinesolution} . \mathrm{com} / \mathrm{wp}-$ content/uploads/2018/12/Apogee_Marine_Series_Leaflet.pdf >. Acesso em 20 de abril de 2020.

SOUZA, A. V.; KRUEGER, C. P. Avaliação da qualidade das profundidades coletadas por meio de ecobatímetro multifeixe. Anais Hidrográficos, Rio de Janeiro, n. 66, p. 90-97, 2009.

TELEDYNE CARIS. HIPS and SIPS. V.11.3. 2020.

TELEDYNE PDS 2000. User Manual Teledyne PDS 2000. V.4.3.11. 2018.

USACE - U.S. Army Corps of Engineers. Hydrographic Surveying. Engineer Manual n. 1110-2-1003. Department of the Army. Washington, D. C. USA, 2013.

WHEATON, G.E. "Patch Test", A System Check For Multibeam Survey Systems, In: PROC.THIRD BIENNIAL U.S. HYDROGRAPHIC CONFERENCE.1988. Baltimore, Maryland - USA. Proceedings...Baltimore.1988. p.85-90.

\section{Biografia do autor principal}

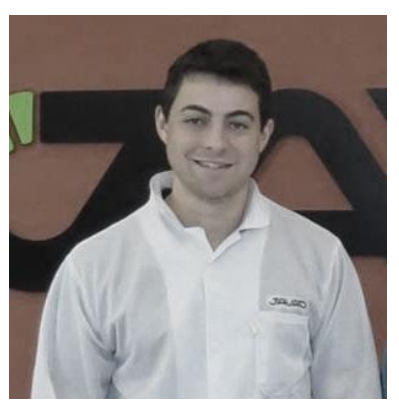

Italo Oliveira Ferreira, nascido em Março de 1988, em Manhuaçu, Minas Gerais, Brasil. Engenheiro Agrimensor e Cartógrafo (2007-2011), com mestrado (20112013) e doutorado (2015-2018) em Informações espaciais (Hidrografia), ambos pela Universidade Federal de Viçosa-UFV. Possui experiência na área de Geociências, com ênfase em Engenharia de Agrimensura e Cartográfica, atuando principalmente nos seguintes temas: Hidrografia, Geodésia, LiDAR, Ajustamento de Observações, Geoestatística e Controle de Qualidade. Atualmente é professor do curso de Engenharia de Agrimensura e Cartográfica da UFV e membro permanente do Programa de Pós Graduação em Engenharia Civil, área de concentração em Informações Espaciais (PGEC/UFV - mestrado e doutorado). 